
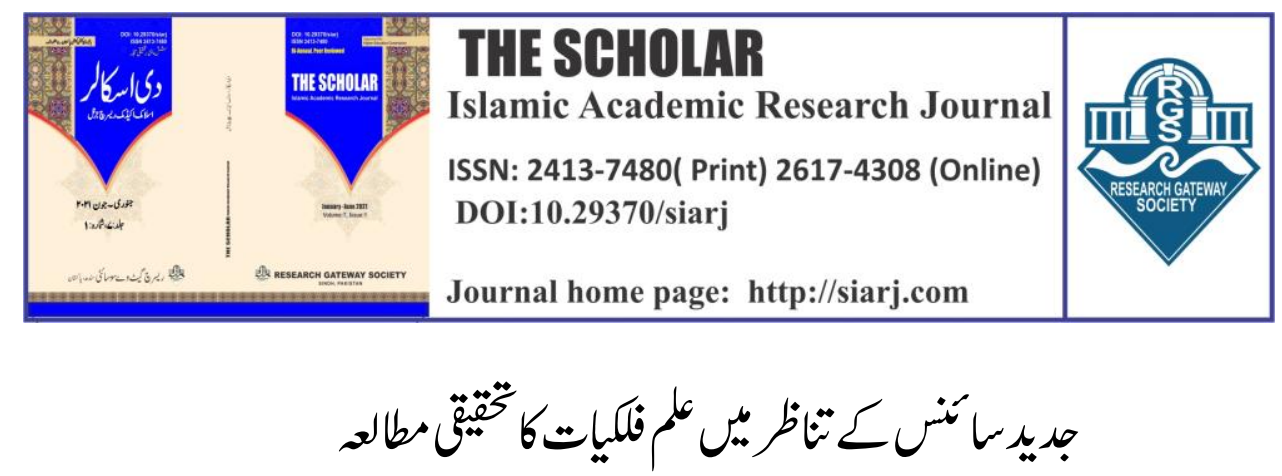

RESEARCH STUDY OF ASTRONOMY IN THE CONTEXT OF MODERN SCIENCE

\section{Maaz Ullah}

Ph.D Scholar, Islamic studies Department, University of Science and Technology Bannu.

Email: zebwazirsng@gmail.com

\section{ORCID ID:}

\section{https://orcid.org/0000-0003-4176-363X}

\section{Fakhar ud Din}

Lecturer, Islamic studies Department of University of Science and Technology. Bannu.

Email: dr.fakhar@ustb.edu.pk

\section{ORCID ID:}

https://orcid.org/0000-0002-2532-0559

To cite this article:

Ullah, Maaz, and Fakhar ud Din. "URDU-RESEARCH STUDY OF ASTRONOMY IN THE CONTEXT OF MODERN SCIENCE." The Scholar-Islamic Academic Research Journal 7, No. 1 (June 30, 2021). http://siarj.com/index.php/Siarj/article/view/312.

To link to this article: https://doi.org/10.29370/siarj/issue12urduar5

\begin{tabular}{ll} 
Journal & $\begin{array}{l}\text { The Scholar Islamic Academic Research Journal } \\
\text { Vol. 7, No. } 1 \text { || January -June 2021 || P. 81-99 } \\
\text { Publisher }\end{array}$ \\
$\begin{array}{l}\text { Research Gateway Society } \\
\text { DOI: }\end{array}$ & $\begin{array}{l}\text { 10.29370/siarj/issue12urduar5 } \\
\text { Uttps://doi.org/10.29370/siarj/ issue12urduar5 }\end{array}$ \\
\hline License: & Copyright c 2017 NC-SA 4.0 \\
Journal homepage & www.siarj.com \\
Published online: & 2021-06-30
\end{tabular}

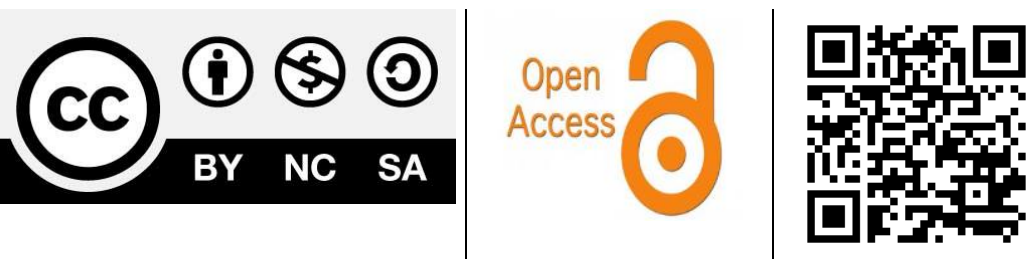




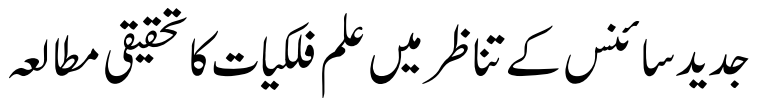 \\ RESEARCH STUDY OF ASTRONOMY IN THE CONTEXT OF MODERN SCIENCE}

\section{ABSTRACT:}

Maaz Ullah, Fakhar Ud Din

Islam is also a complete code of life as well as a religion that monitors all the variations that belong to human beings and the universe's appearance and external existence. It is a Muslim fact that Islam gave humanity based on lightweight in the Greek philosophy, and provided modern science basis. Today's period of science is far away. Therefore, the right and outstanding publication of religion in the present can be better performed on a modern scientific basis. In this period, the need for this period is more than the last centuries that Muslim societies should promote the promotion of modern science connecting religious education to scientific education, and the truth should be said to Islam. So today's Muslim student is a mutual relationship between religion and science to understand the light of the Quran and Sunnah.

KEYWORDS: Islam, Astronomy,Technology, Science, Quran Science, Modern Era

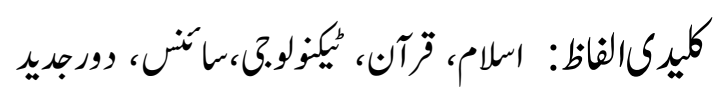

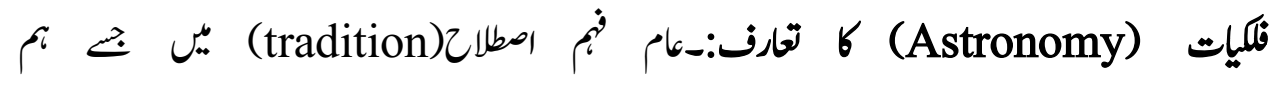

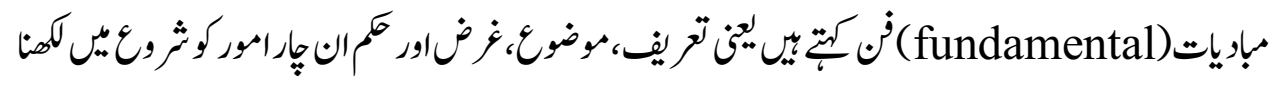

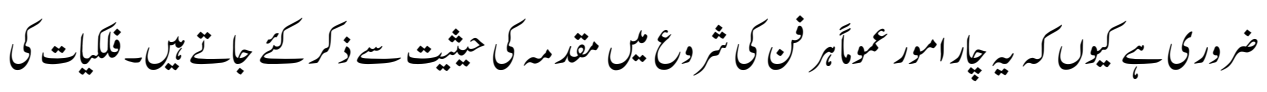

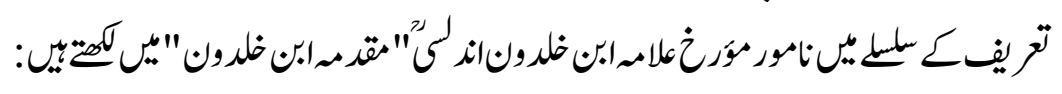




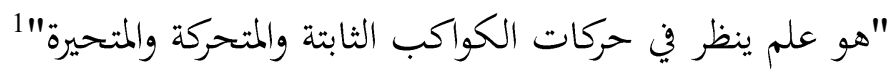

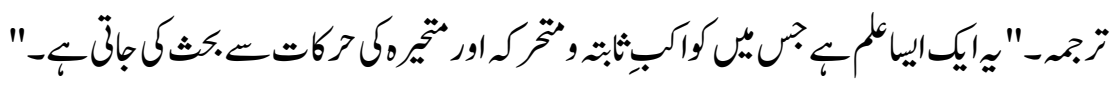

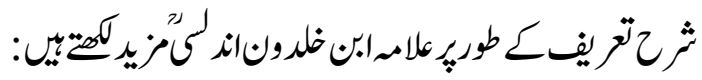

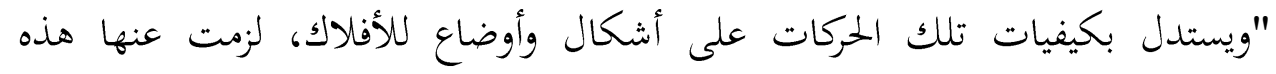

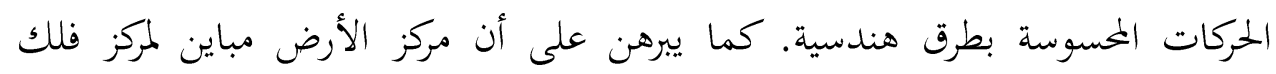

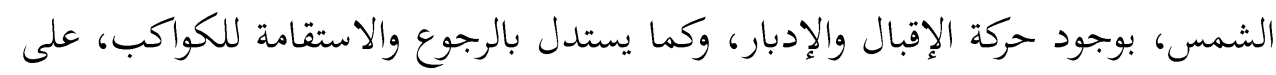

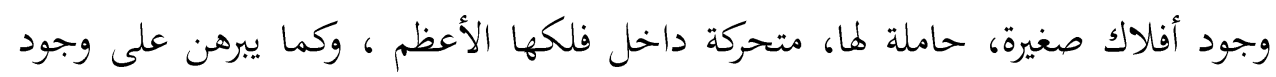

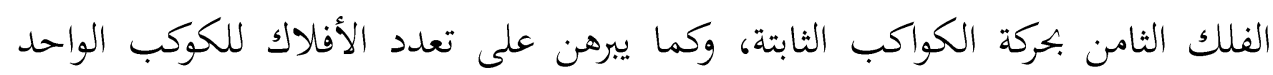
بتعداد الميول له، وأمثال ذلك."2

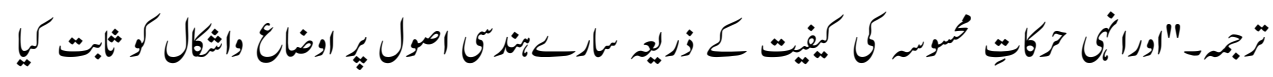

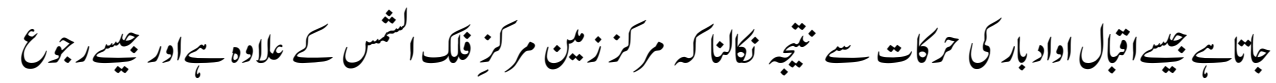

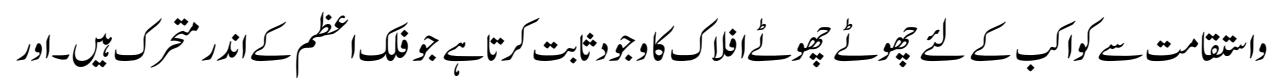

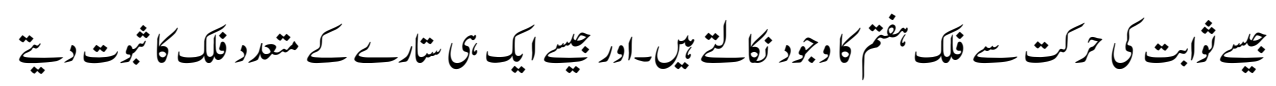

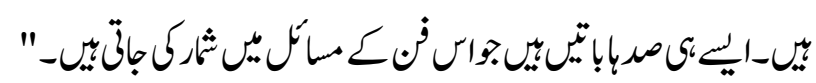

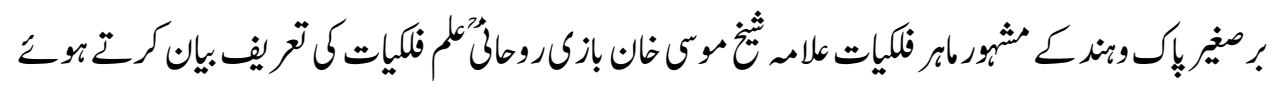

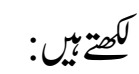
"علم يعرف به احوال العالم الجسماني من المجرات والنجوم والشمس والسيارات وغيرها من حيث الحركت والبعد والتكون وما يتعلق بذلك بقدر الطاقه البشرية"

${ }^{1}$ Undlusi, Abu zaid,Abdul Rehman bin Muhammad, Ibn Khaldoon, Muqaddama Ibn Khaldoon, Dar Ahya alturas Al Arabi, Labnan, 1996, $1 / 296$

${ }^{2}$ Ibid

${ }^{3}$ Bazi Roohani, Muhammad Musa Khan, Al-Hay'at Al-Wusta, Idara Tasneef wa Adab, Lahore, 1999, P-7 


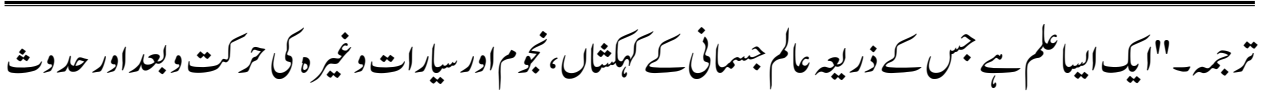

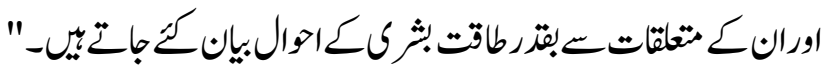

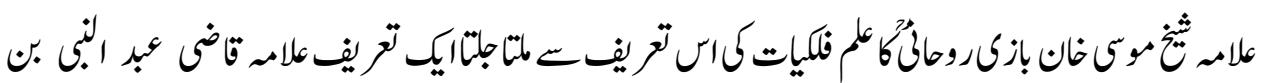

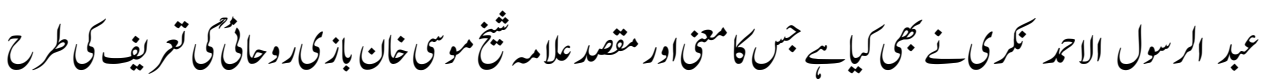

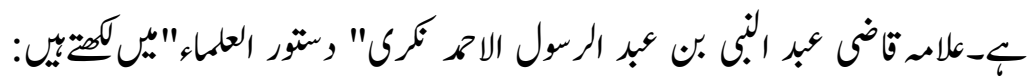
"هو الذي يبحث فيه عن أحوال الأجرام البسيطة العلوية والسفلية من حيث الكمية والكيفية والوضع والحركة اللازمة لها أبدية أو ممتنعة الانفكاك وما يلزم منها" 4

\section{علم فلكإتكاموضوع:}

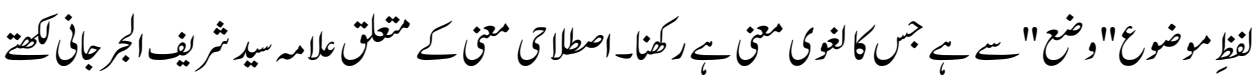
بّ: "ما يبحث فيه عن عوارضه الذاتية، كبدن الإنسان لعلم الطب؛ فإنه يبحث فيه عن أحواله

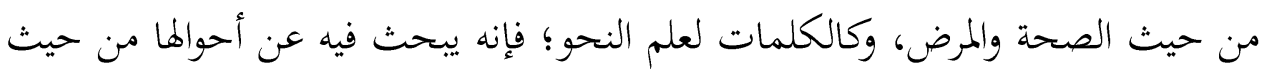

$$
\text { الإعراب والبناء" }
$$

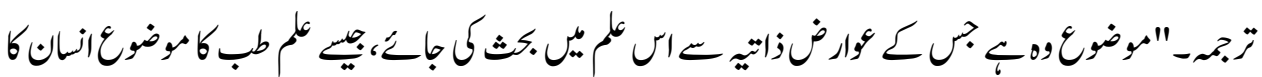

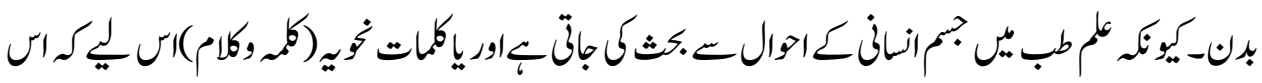

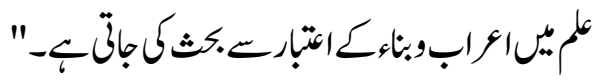

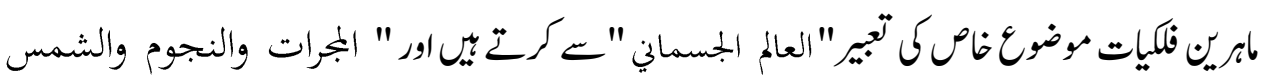

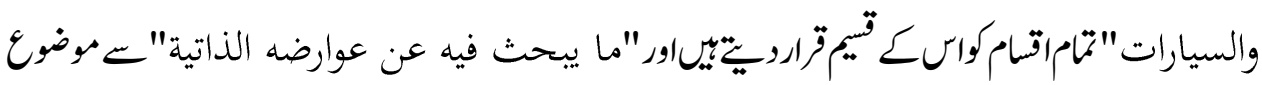

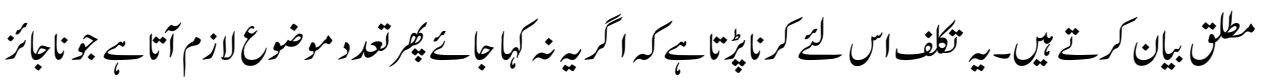

${ }^{4}$ Nakri, Qazi Abdul Nabi bin Abdun Rasool, Dastoor ul Ulama, Dar alkutub Al-Ilmia, Labnan, 2000, 3/331

${ }^{5}$ Jurjani, Ali bin Muhammad, Kitab ul Tareefat, Dar alkutub Al-Ilmia, Labnan, 1983, P-236 


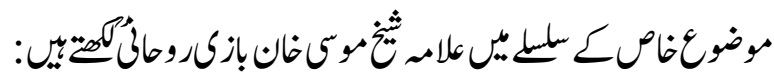
"واما موضوعه فهو العالم الجسماني واجرامه من الجُرات والنجوم والذي اشتمل عليه النظام الشمسي باعتبار الحيثية المذكورة في الحد"

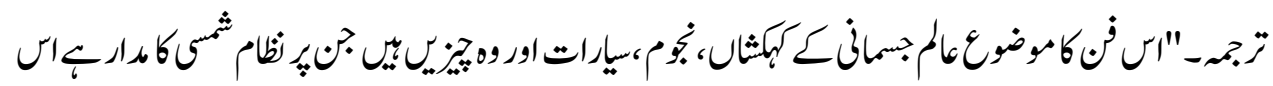

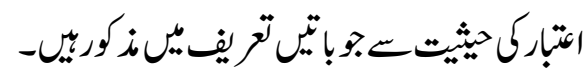

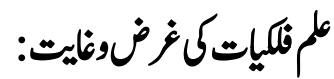

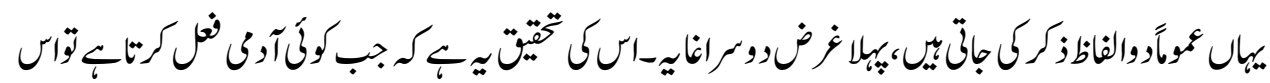

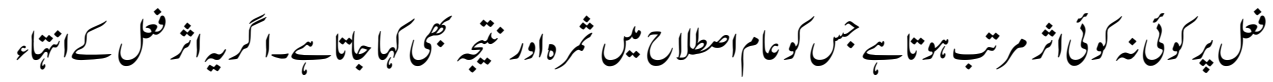

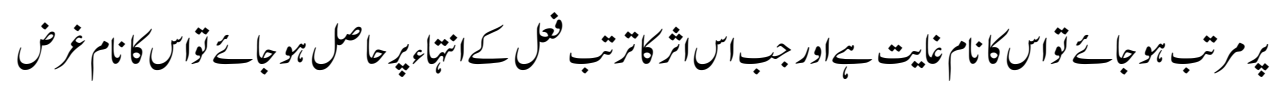

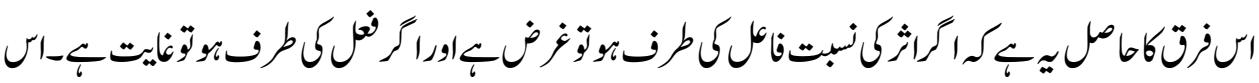

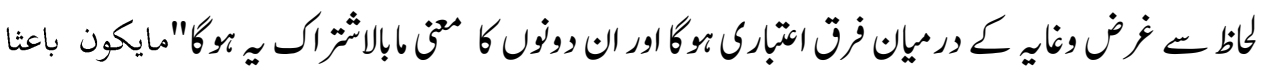

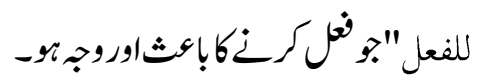

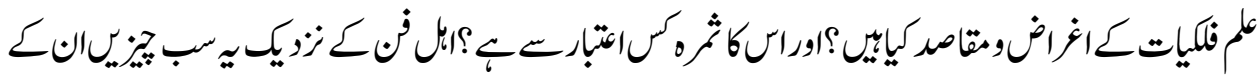

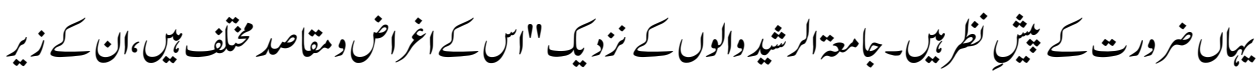

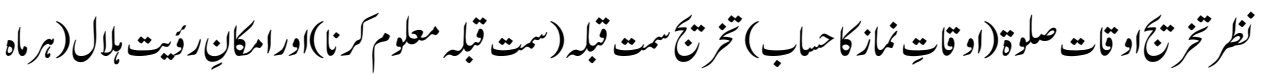

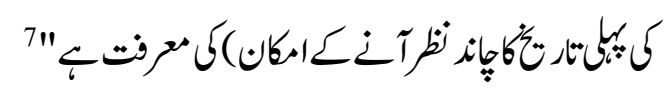

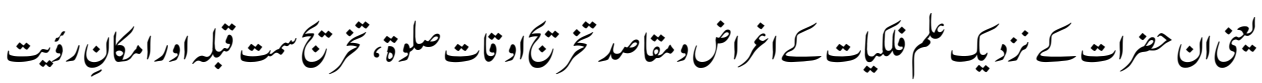

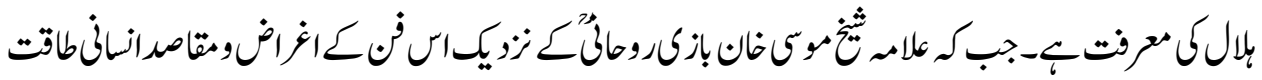

\footnotetext{
${ }^{6}$ Al-Hay'at Al-Wusta, P-8

${ }^{7}$ Mufti Muhammad Sultan Alam, Mukhtasar Falkiyat, maktaba AlSaaadat, Karachi, 2013, P-7
} 


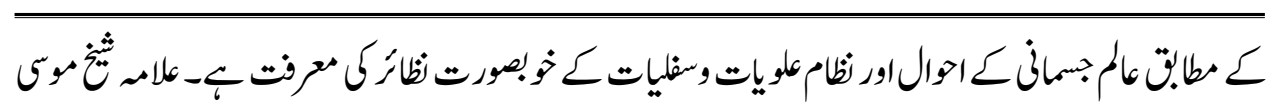

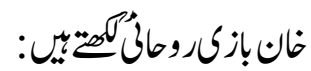
"واما غايته فهي معرفة احوال العالم الجسماني وجميل نظام العلويات والسفليات بقدر الاستطاعة" 8

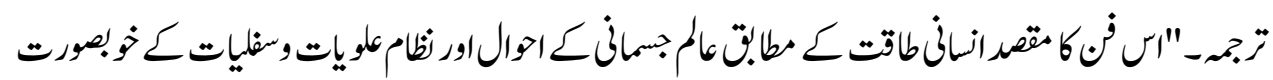

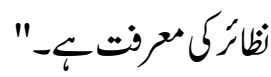

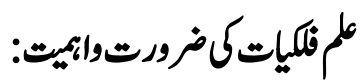

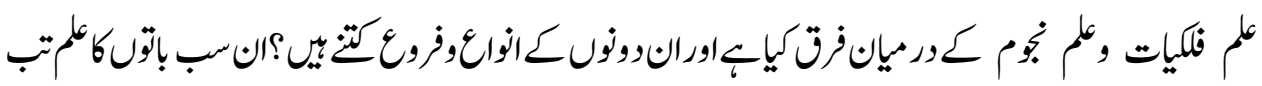

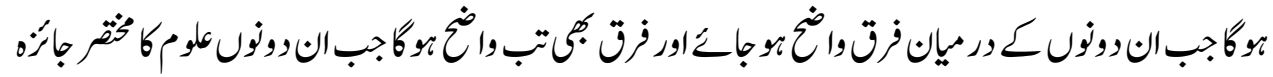
ليإباح-

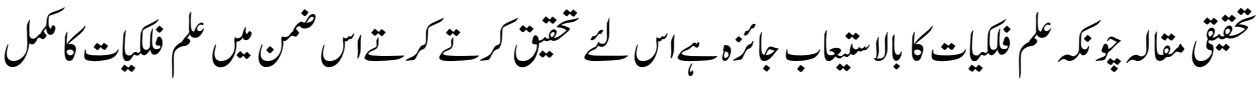

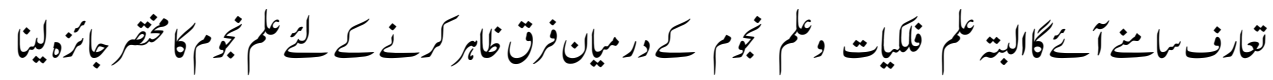

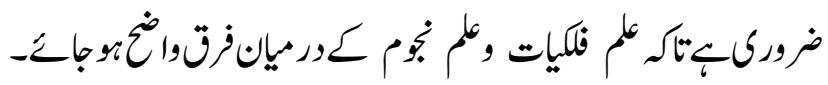

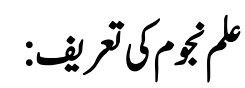

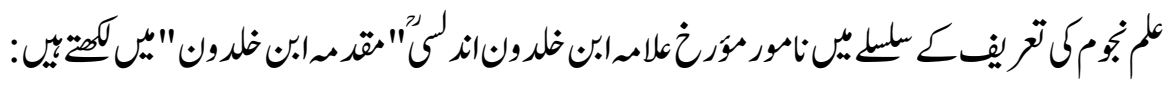
"يعرفون بها الكائنات في عالم العناصر قبل حدوثها، من قبل معرفة قوى الكواكب و تأثيرها

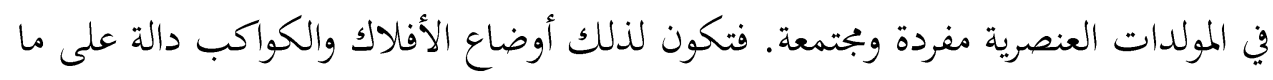
سيحدث نوع من أنواع الكائنات الكلية والشخصية." 9

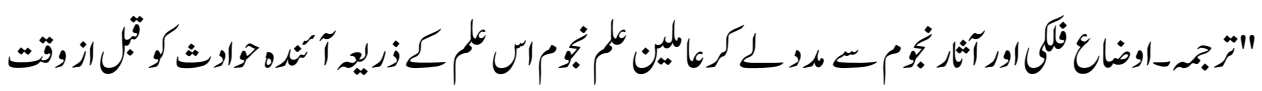

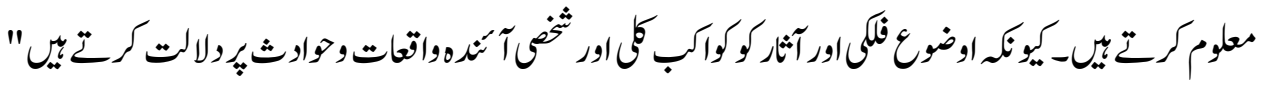

${ }^{8}$ Al-Hay'at Al-Wusta, P-9

${ }^{9}$ Muqaddama Ibn Khaldoon, 1/332 


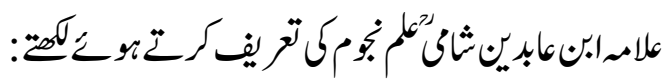

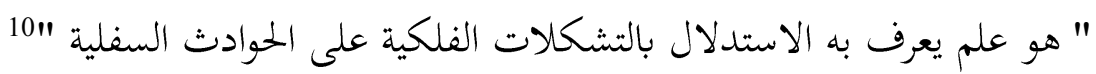

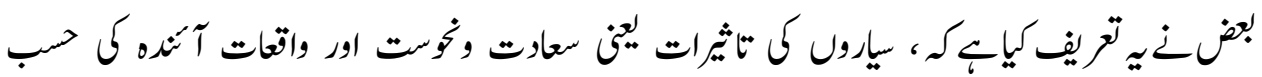

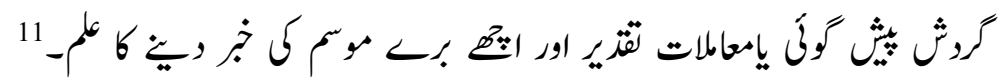

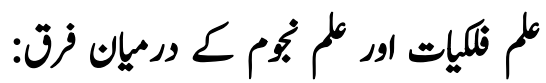

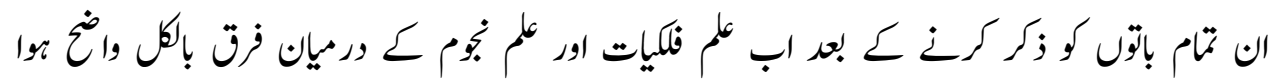

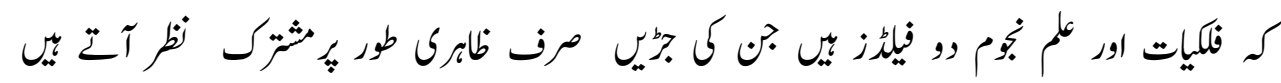

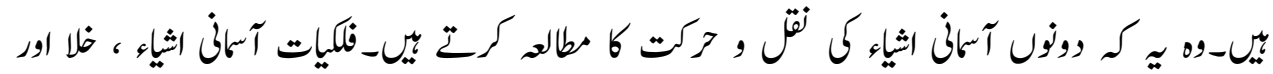

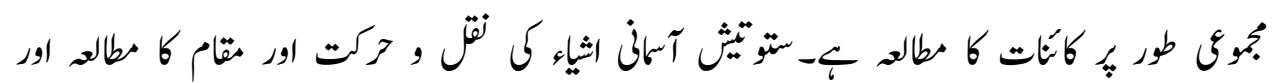

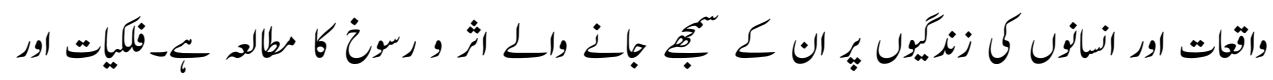

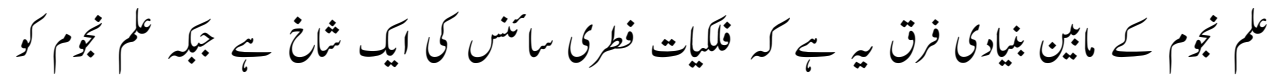

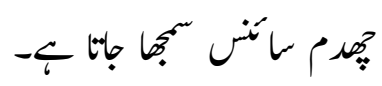

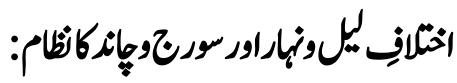

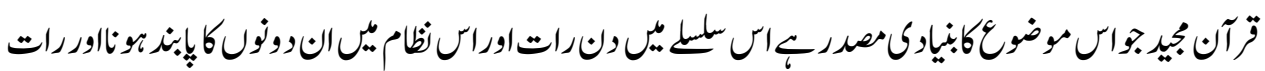

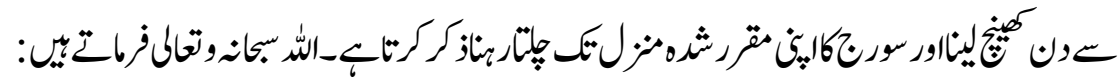

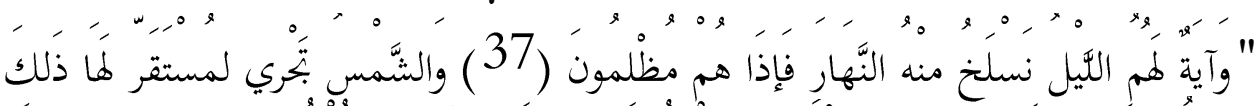

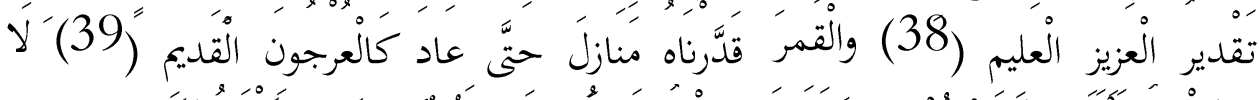

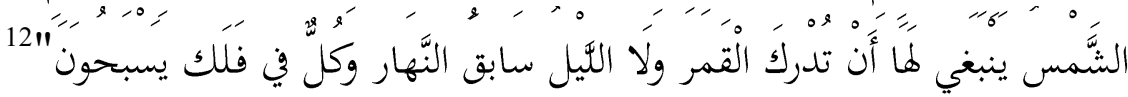

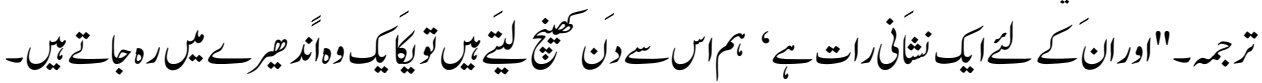

${ }^{10}$ Shami, Ibn-e-Abideen, Muhammad Ameen Bin Umar, Aldamashqi AlHanafi, Rad-Al-Muhtar Ala Al-Dur Al-Mukhtar, Dar Al-Fikar, Labnan, 1412 A.H. $1 / 43$

${ }^{11}$ Urdu Lughat, Urdu Press Karachi, 1991, V.13, P-519

${ }^{12} \mathrm{Al}-$ Quran, Sora Yaseen, 37 


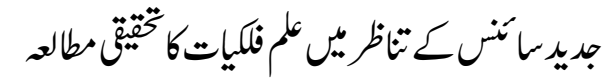

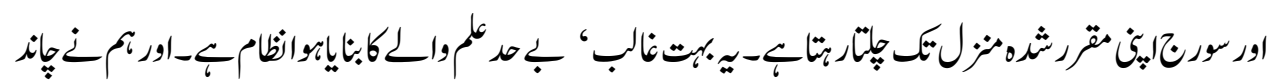

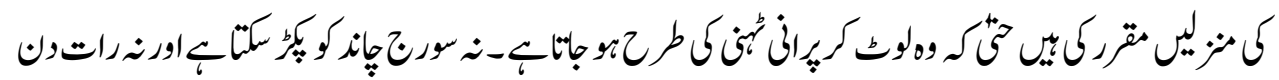

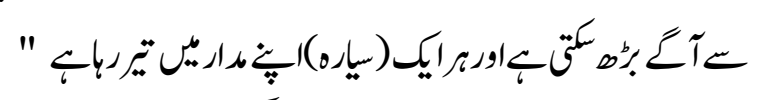

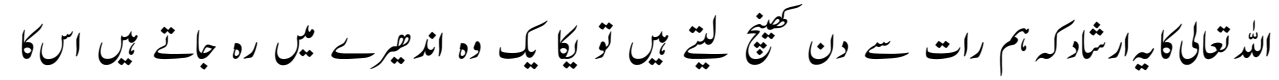

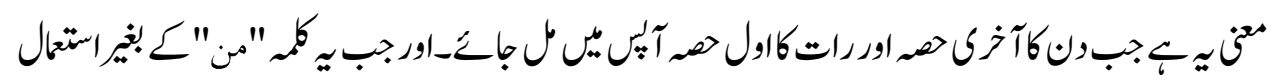

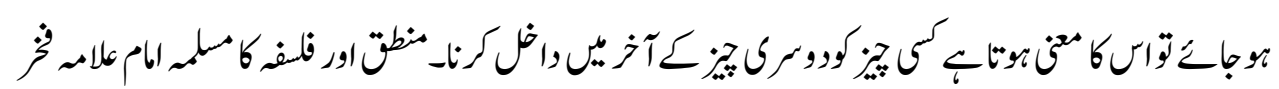

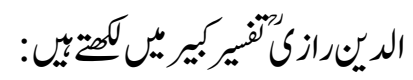
"معناه تمييزه منه يقال انسلخ النهار من الليل إذا أتى آخر النهار ودخل أول الليل وسلخه

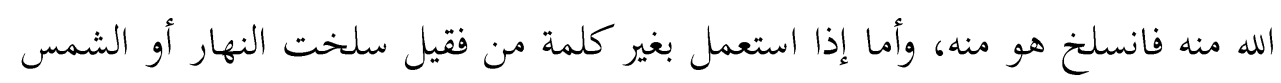
فمعناه دخلت في آخره " 13

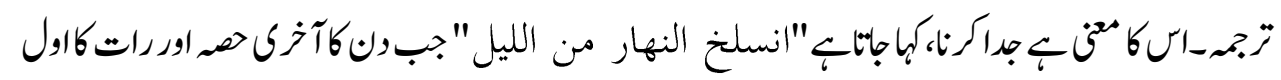

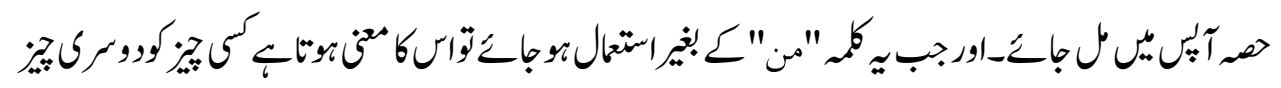

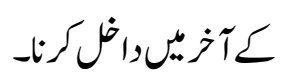

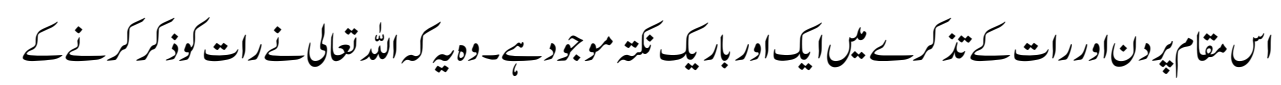

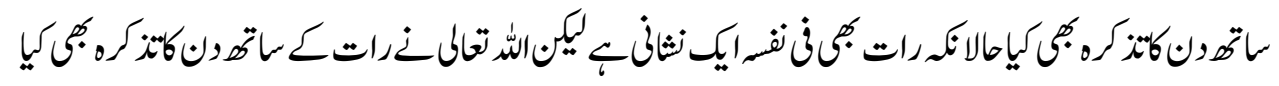

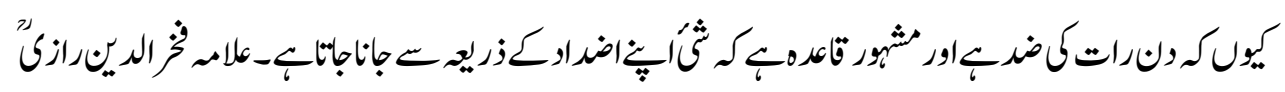

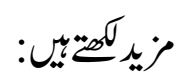
" فإن قيل فالليل في نفسه آية فأية حاجة إلى قوله: نسلخ منه النهار؟ نقول الشيء تتبين بضده منافعه ومحاسنه

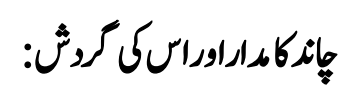

${ }^{13}$ Razi Abu Abdullah Muhammad Bin Umar Altamimi, Altafseer Al-Kabeer, Dar Ahya Al-Turas Al-Arabi, Labnan, 1420 A.H. V.26, P-275 ${ }^{14}$ Ibid 


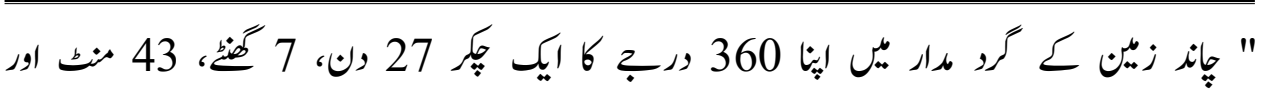

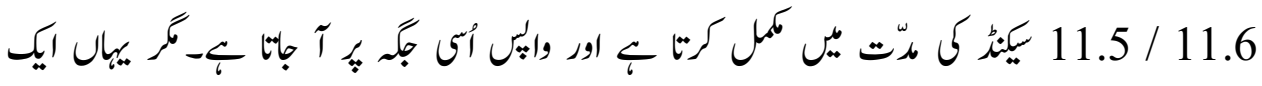

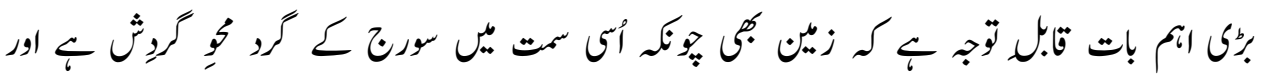

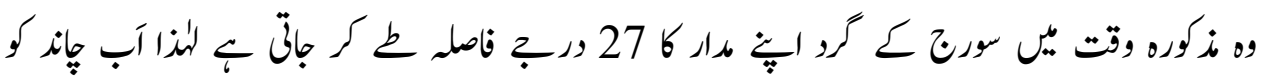

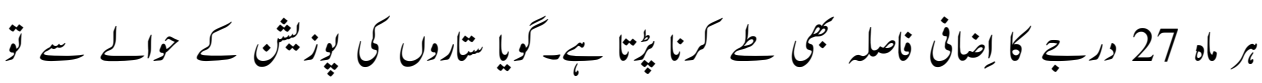

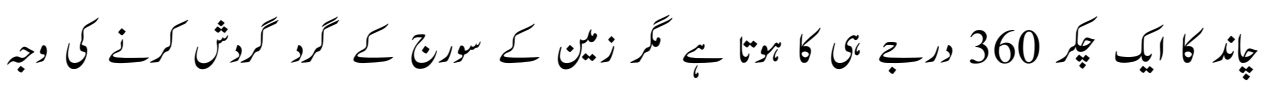

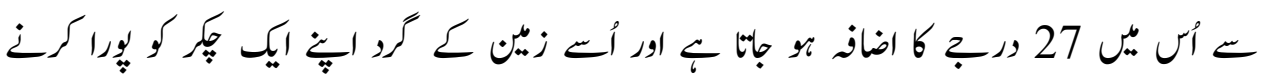

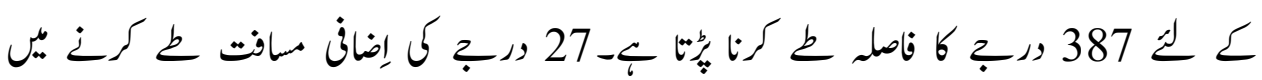

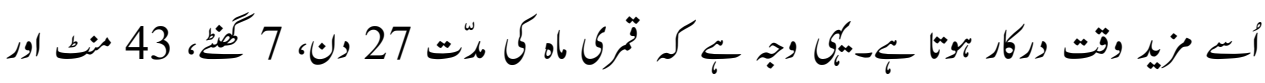

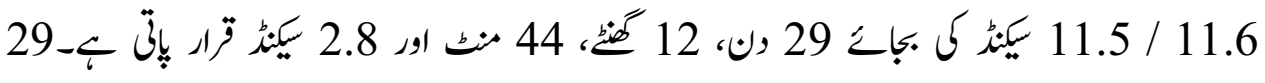

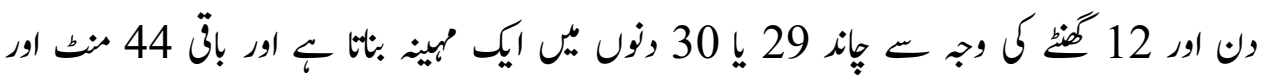

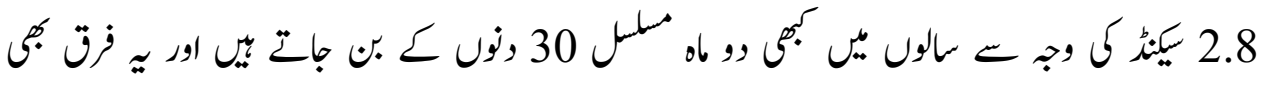

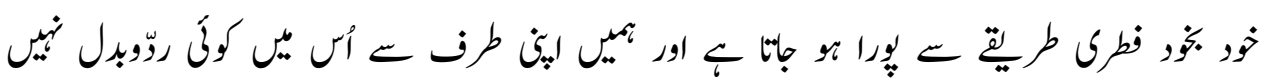

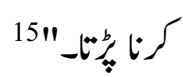

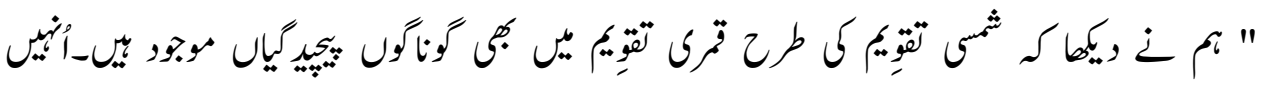

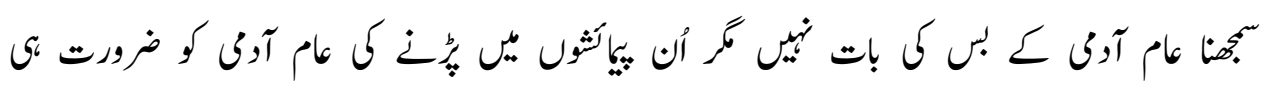

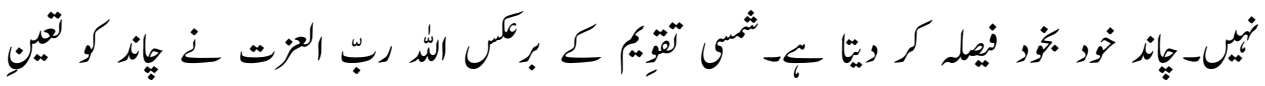

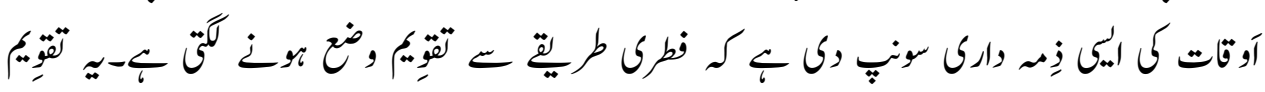

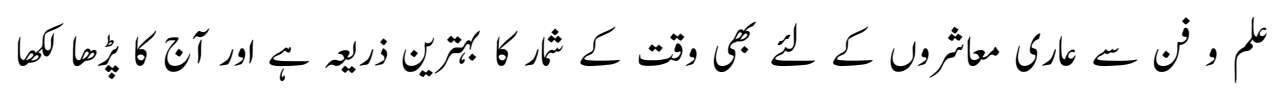

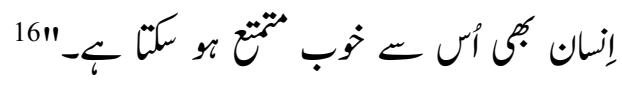

${ }^{15}$ Qadri Allama Muhammad Tahir, Islam aor Jadeed Science, Minhaj ALQuran Publications, Lahore, 2001, P-305 ${ }^{16} \mathrm{Ibid}$ 


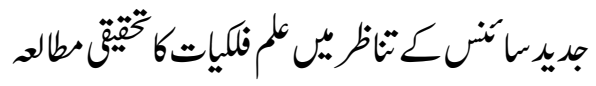

\section{بكي ،ول (Black Hole):}

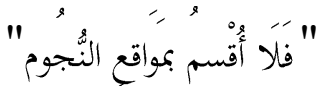

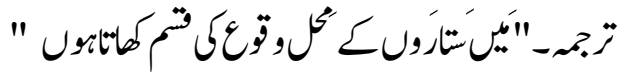

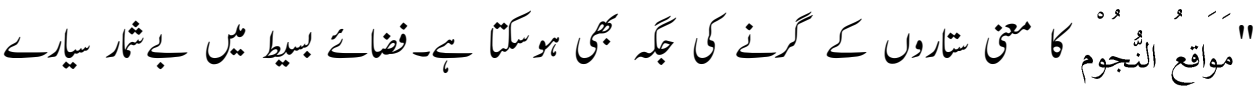

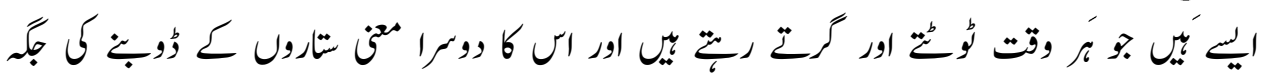

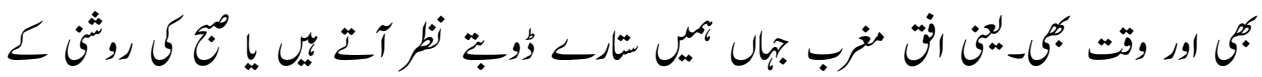

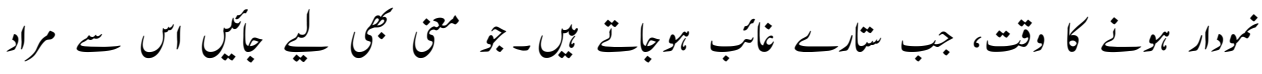

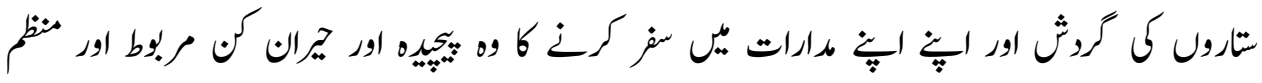

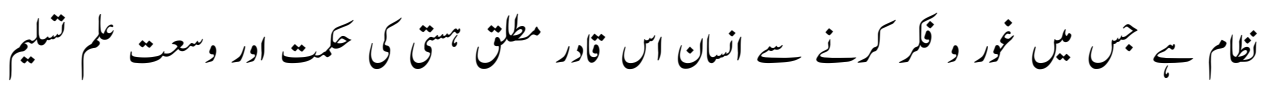

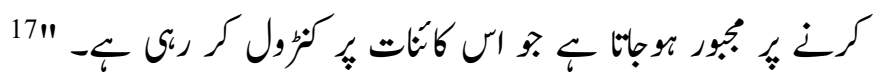

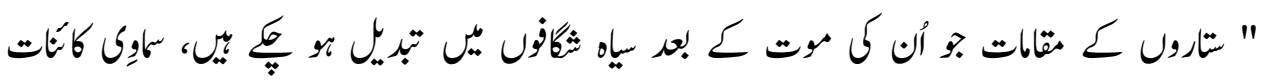

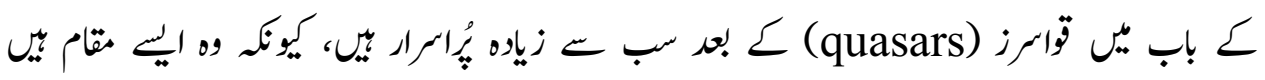

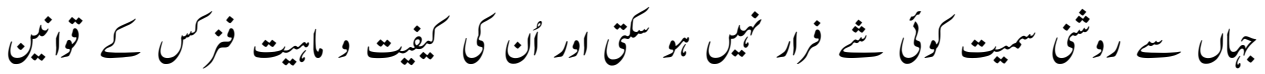

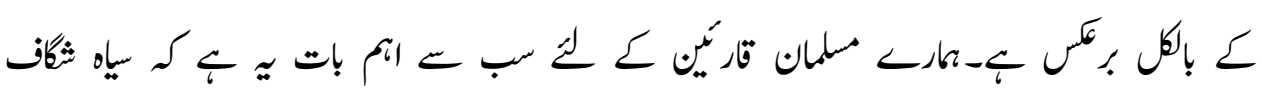

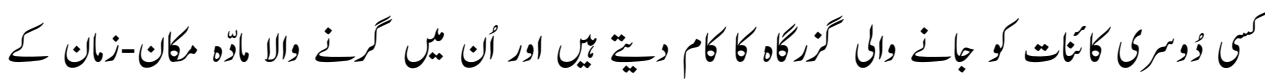

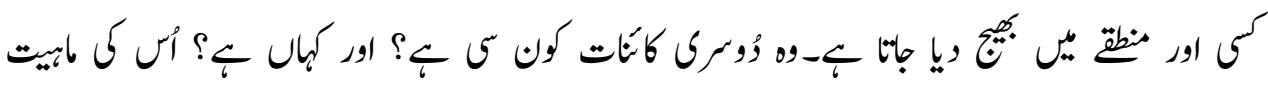

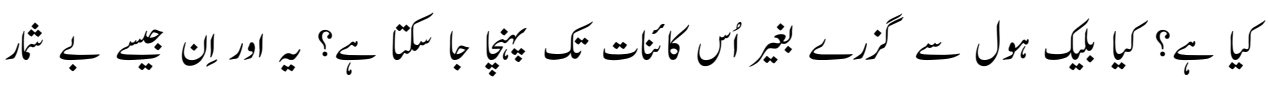

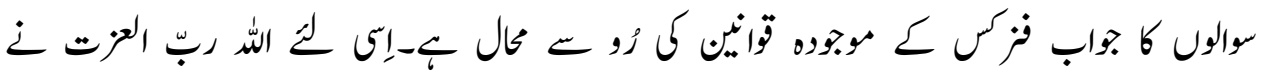

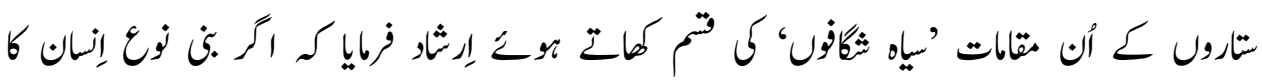

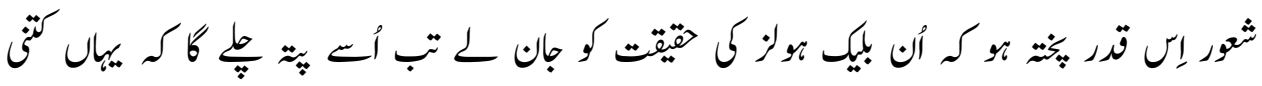

\footnotetext{
${ }^{17}$ Kailani Allama Abdul Rahman, Tafseer Taiseer Al-Quran, Maktaba Alsalam, Lahore, 2000, V.4, P-366
} 


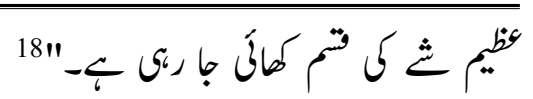

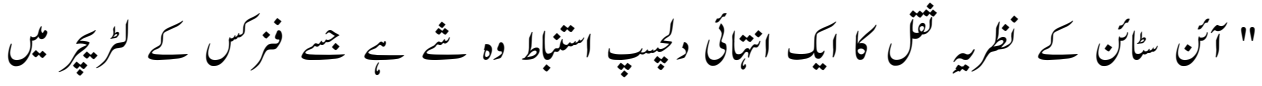

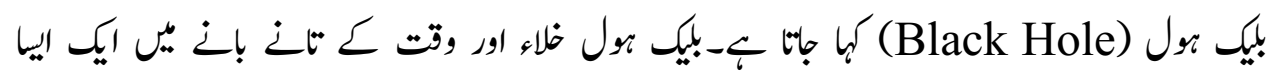

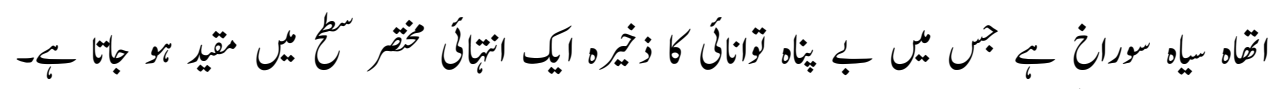

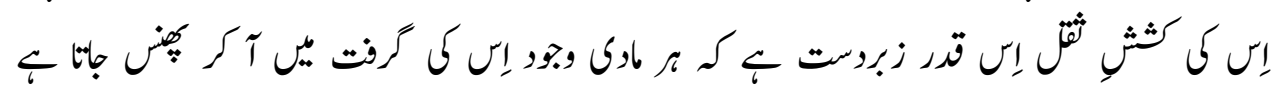

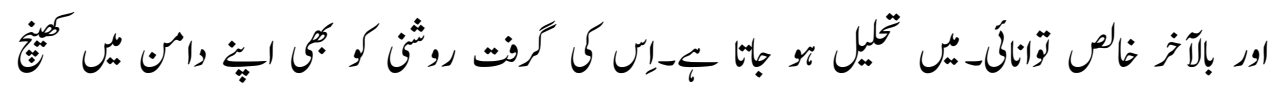

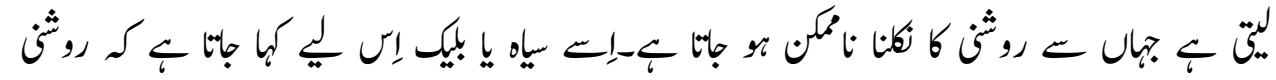

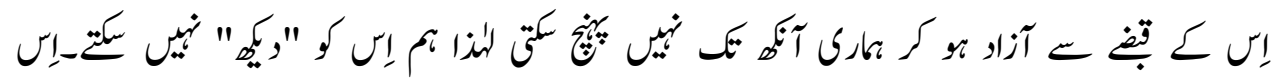

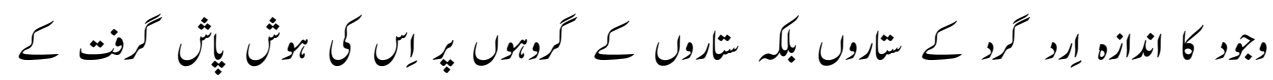

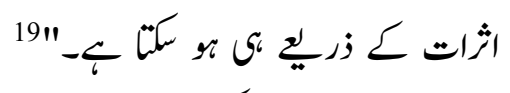

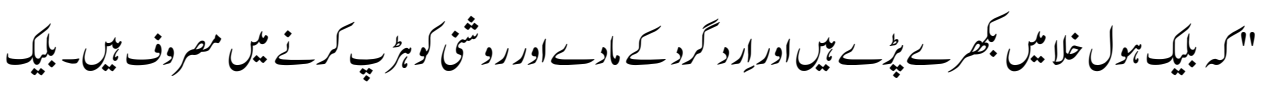

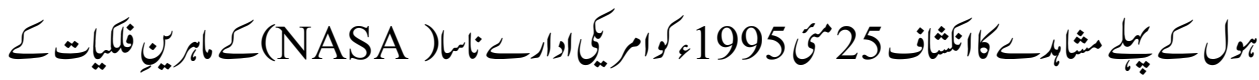

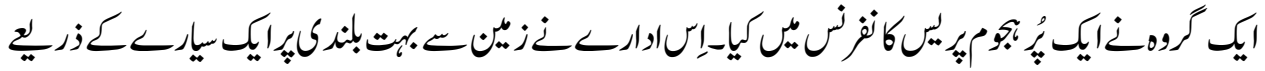

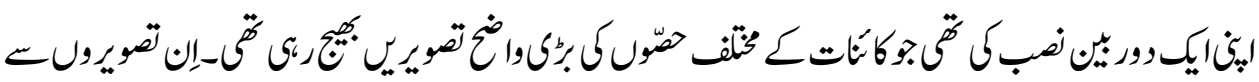

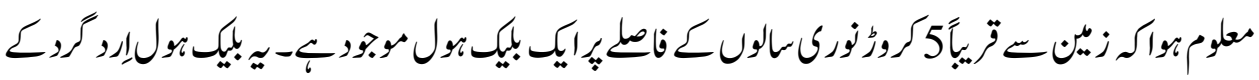

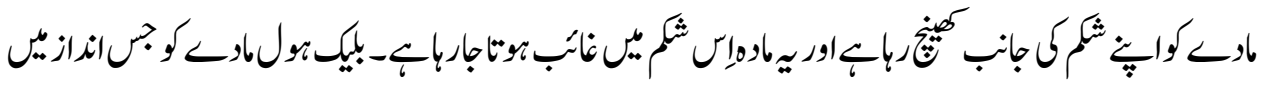

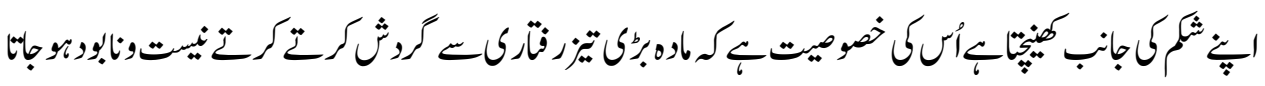
$2011-\sum_{6}$

وروج (The Sun):

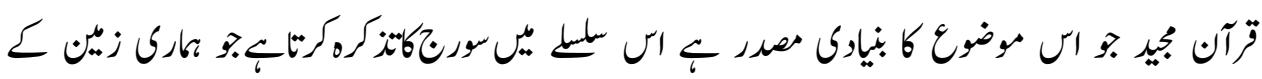

${ }^{18}$ Islam aor Jadeed Science, P-282

${ }^{19}$ Tahseen Ullah, Mutala Falkiyat, Matan, 2016, P-227

${ }^{20}$ Dr. Mujahid Kamran, Jadeed Tabeyat ke Bani, Matan, 1997, P-365 


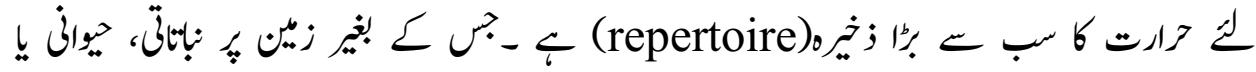

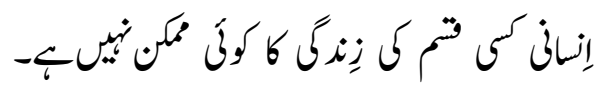

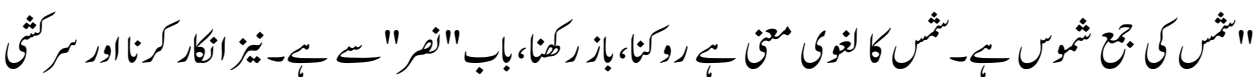

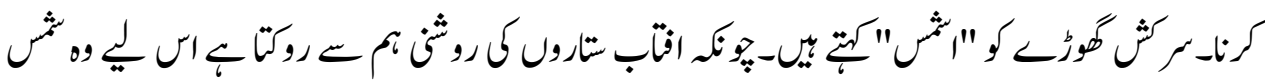

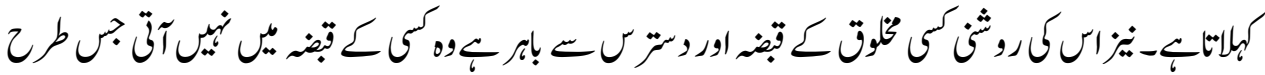

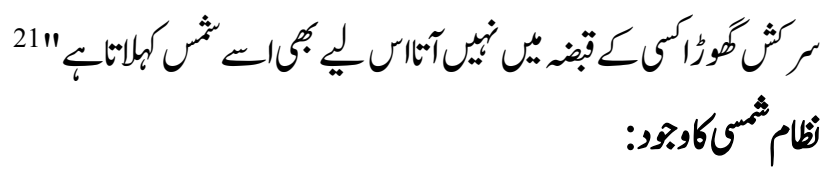

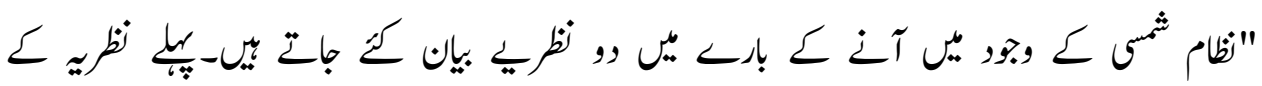

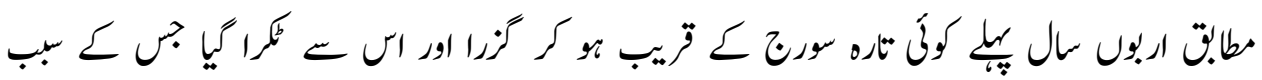

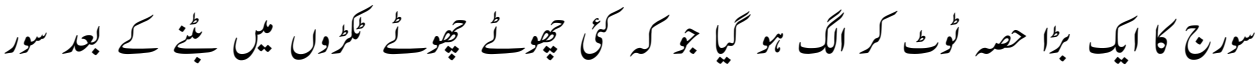

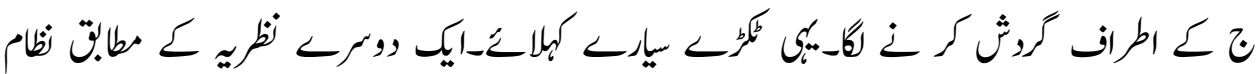

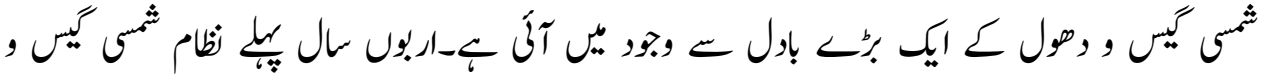

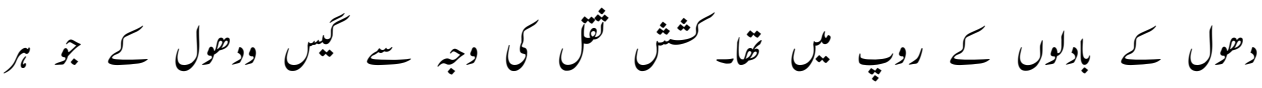
(Atom)

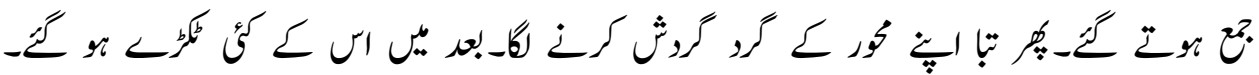

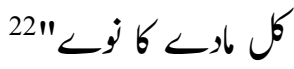

: The Moon)

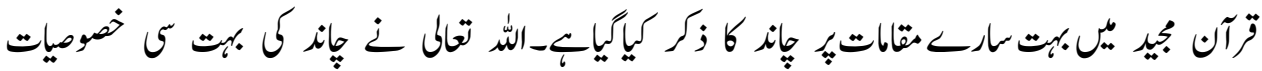

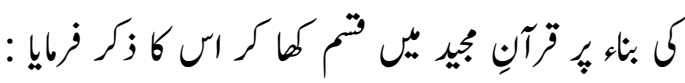

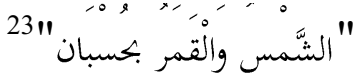

${ }^{21}$ Al-Hayat al-wusta ma Sharhiha Al-Nujoom Al-nashta, P-40

${ }^{22}$ Sahanbali, Muhammad Furqan, Aena Falkiyat, Al-Qazi Printers, New Dihli, 2004, P-142

${ }^{23}$ Al-Quran, Sorah AL-Rahman: 5 


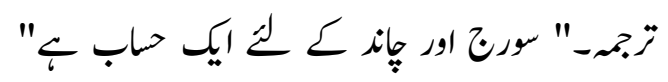

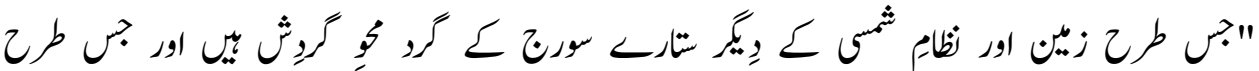

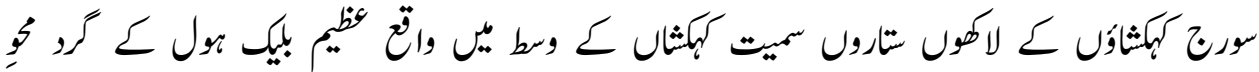

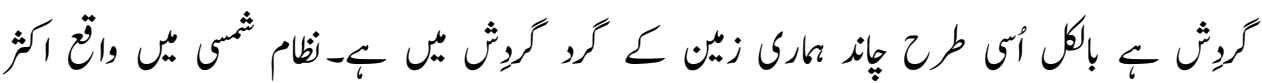

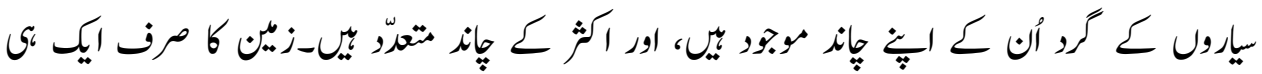

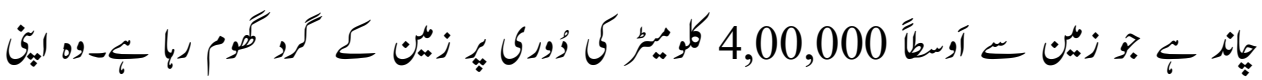

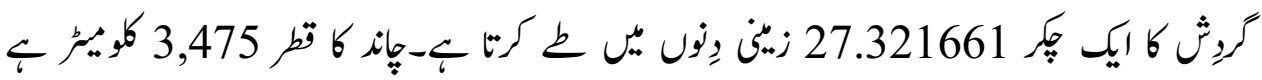

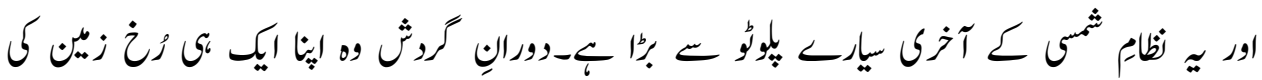

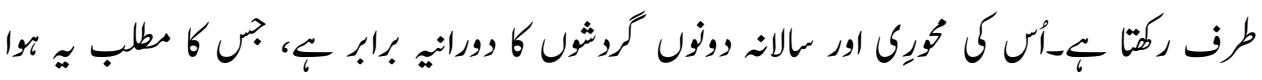

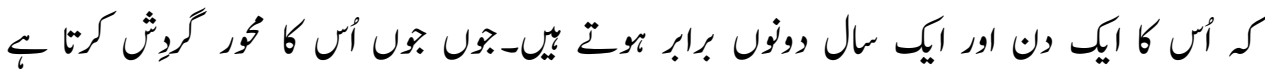

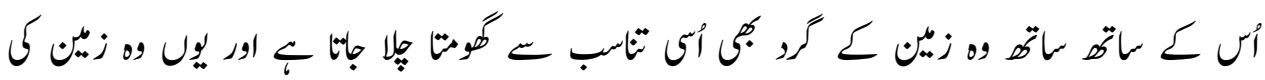

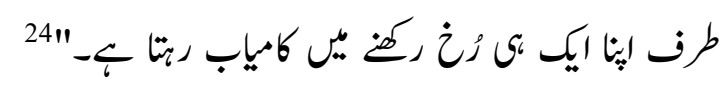

\section{ترى تقوّم (Lunar Calendar):}

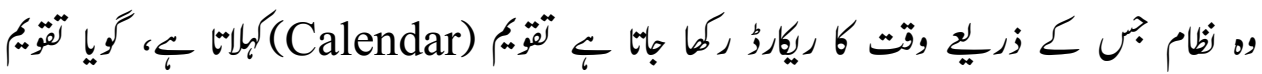

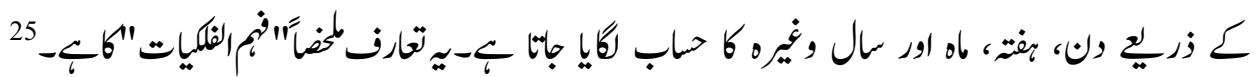

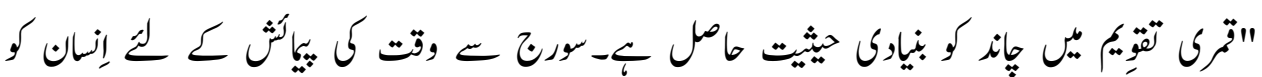

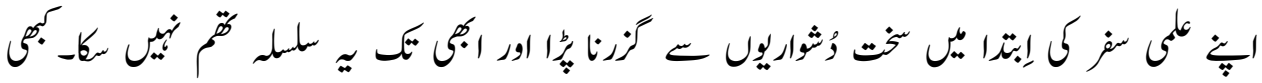

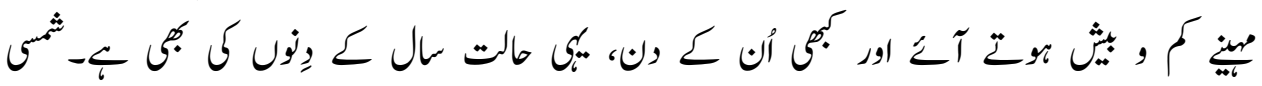

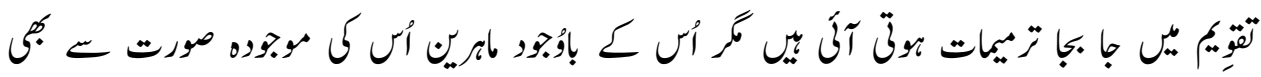

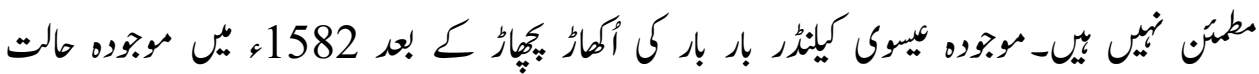

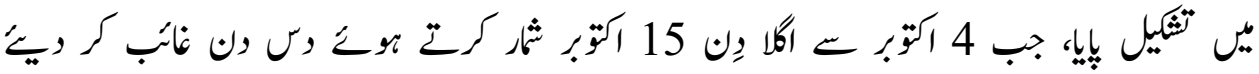

\footnotetext{
${ }^{24}$ Islam aor Jadeed Science, P-304

${ }^{25}$ Fahm-e-Falkiyat, Maktaba tul Maarif, Karachi, 1431 A.H. P-53
} 


\section{The Scholar Islamic Academic Research Journal}

Vol. 7, No. 1 || January -June 2021 || P. 81-99

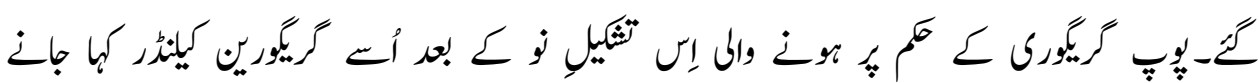

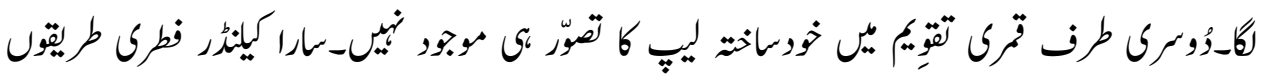

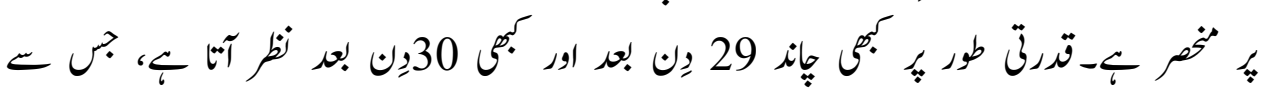

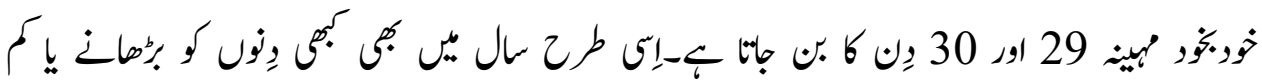

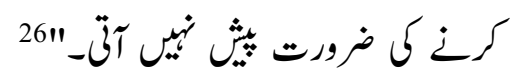

زمئ (The Earth)

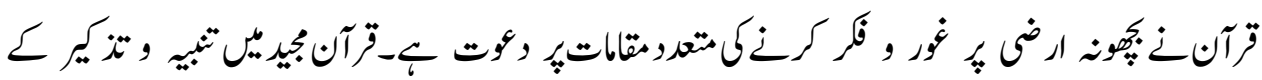

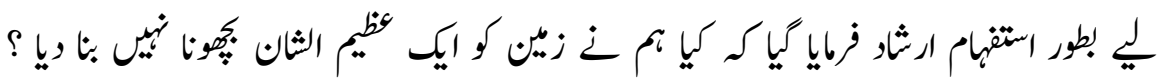

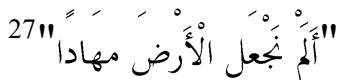

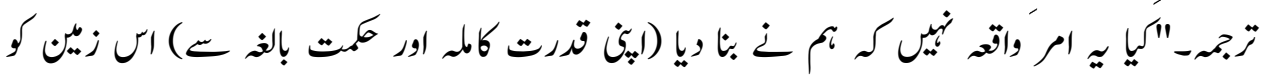

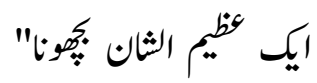

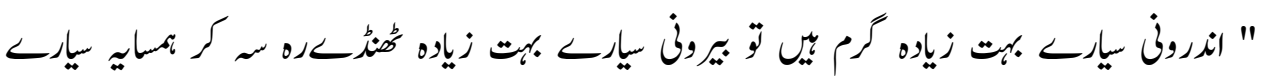

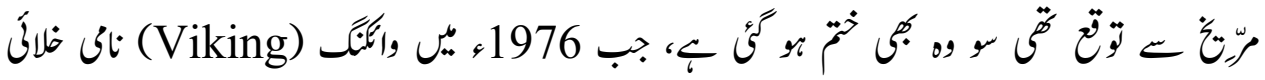

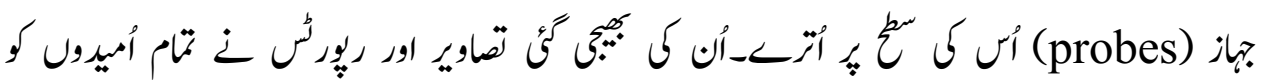

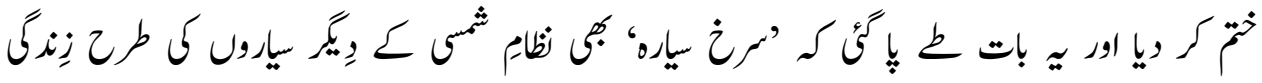

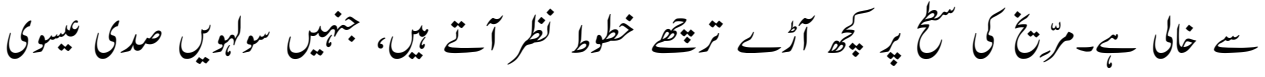

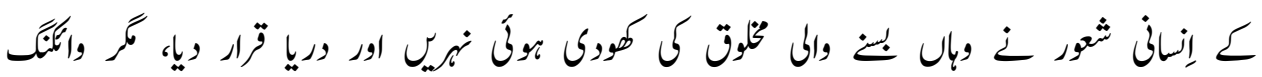

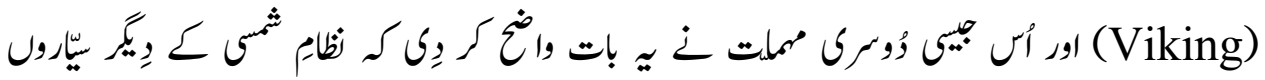

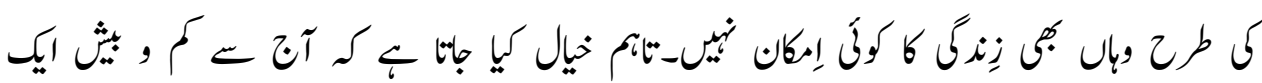

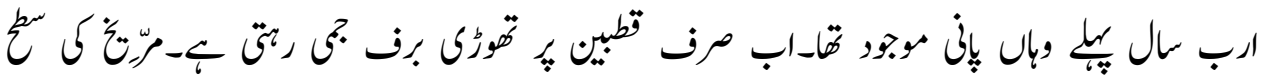

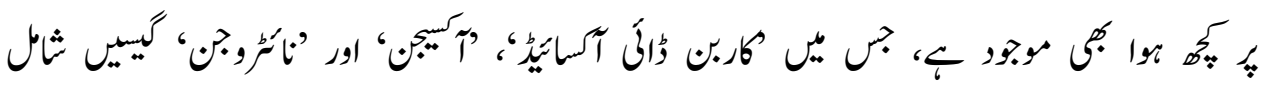

\footnotetext{
${ }^{26}$ Ibid

${ }^{27}$ Al-Quran, Soorat AL-naba:6
} 


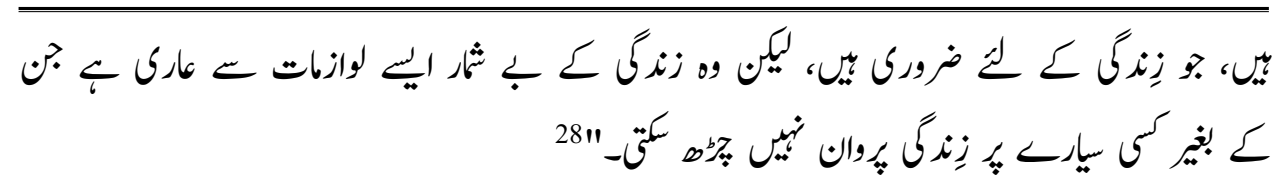

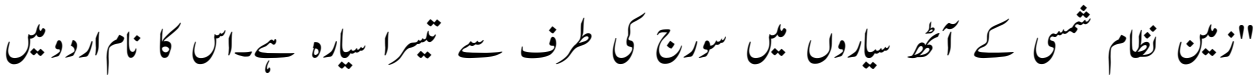

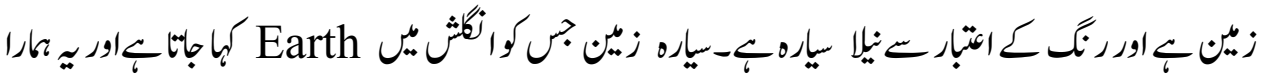

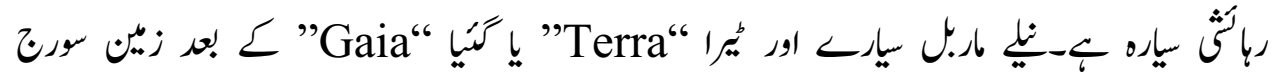

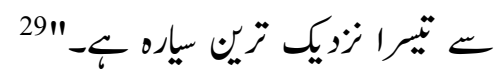

آسمأنجم مئ(Constellations):

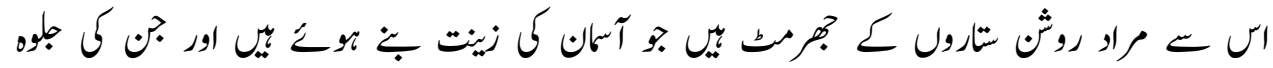

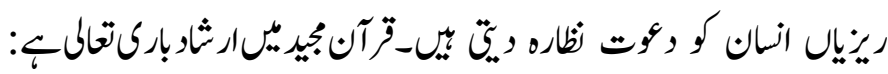

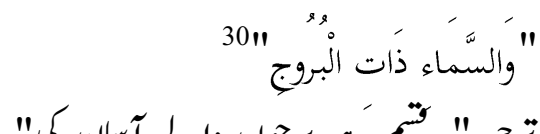

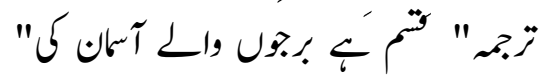

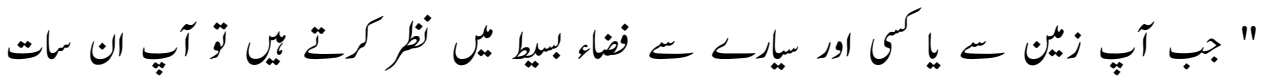

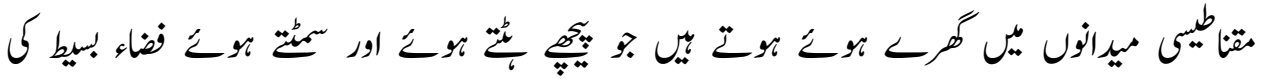

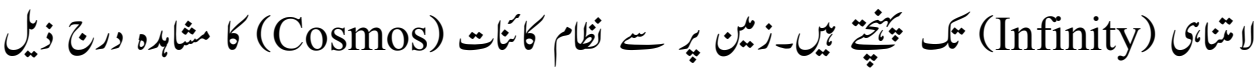
קريقت

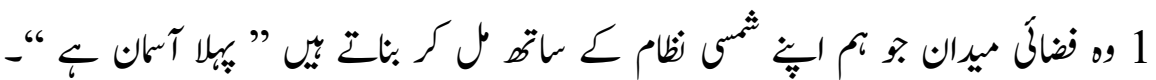

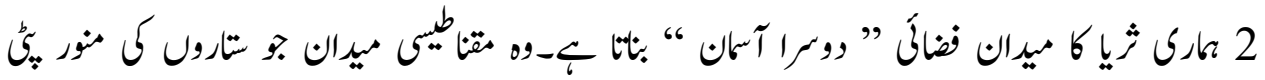

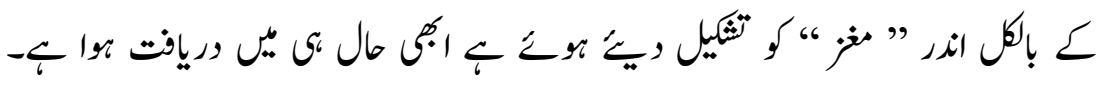

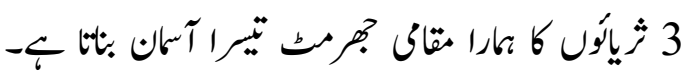

\footnotetext{
${ }^{28}$ Islam aor Jadeed Science, P-295

${ }^{29}$ Archibald, w.Handry, “Age of The Earth”, chap:2,page:451

${ }^{30}$ Al-Quran, Soorat AlÉ-Burooj:1

${ }^{31}$ Dr. Noor Baqi Halook, Quraani Ayat aou Saience Haqaiq, Indus

Publishing, Karachi, 2014, P-131
} 


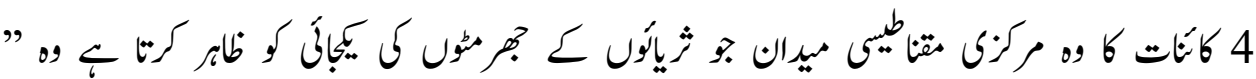

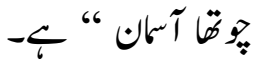

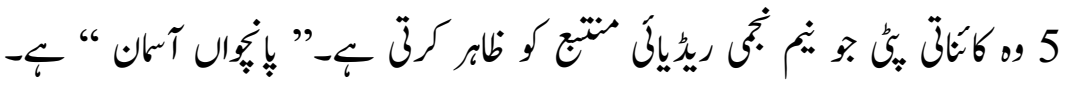

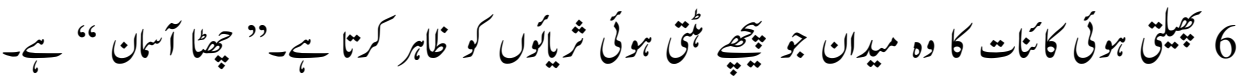

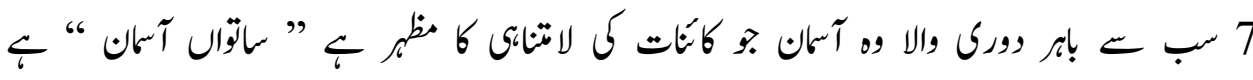
$32 "$

\section{كات آساونكازَآنتصور(Conception):}

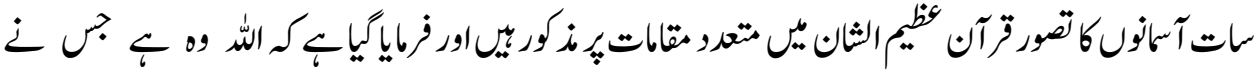

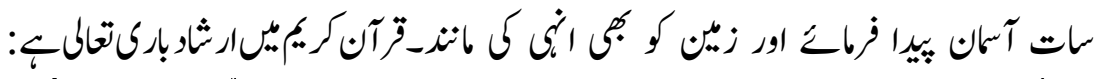

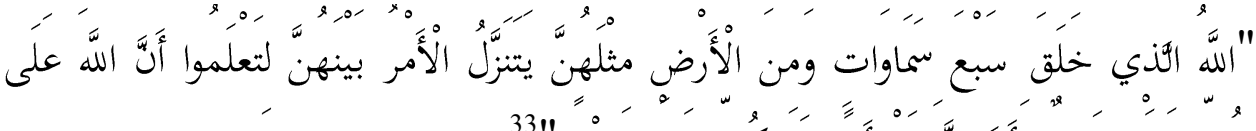

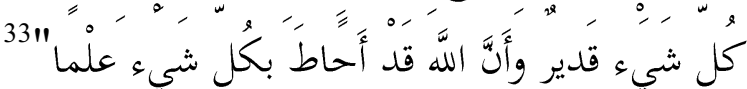

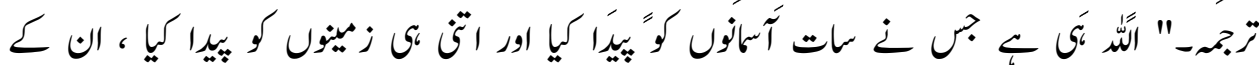

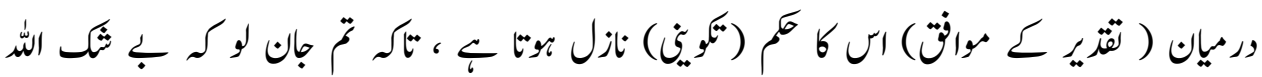

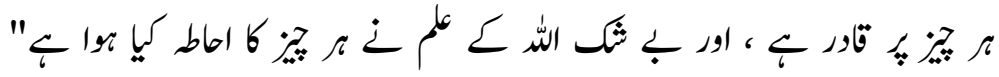

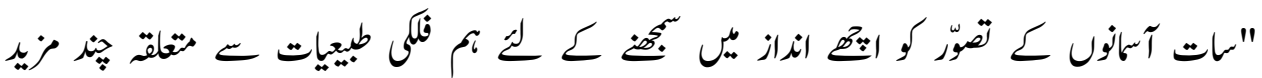

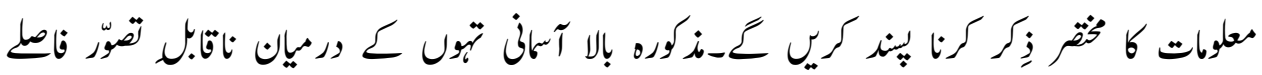

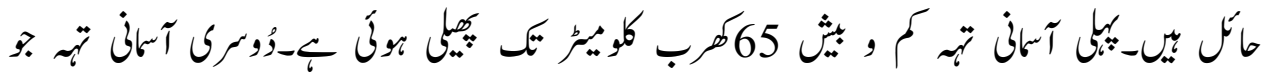

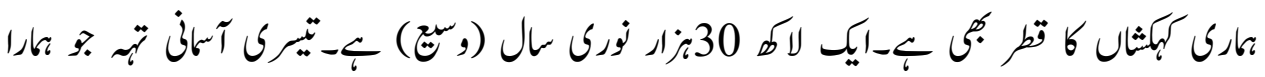

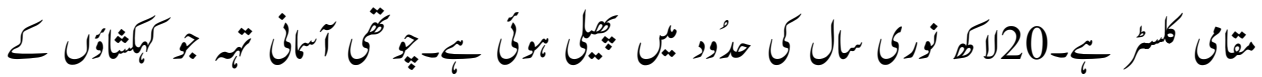

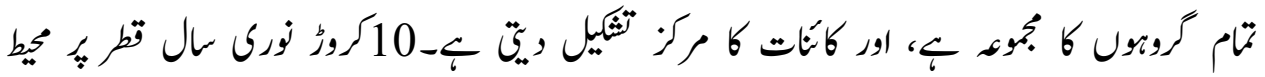

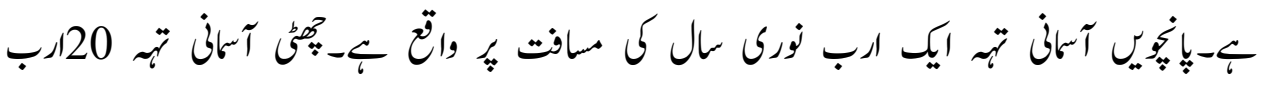

\footnotetext{
${ }^{32}$ Ibid

${ }^{33}$ Al-Quran, Soorat al-Talaq:12
} 


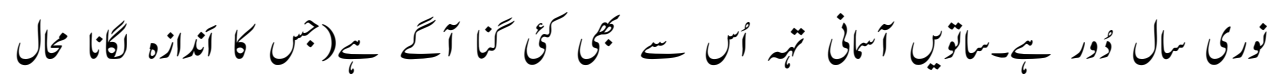

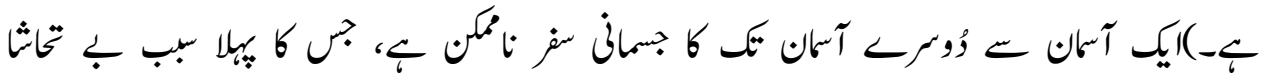

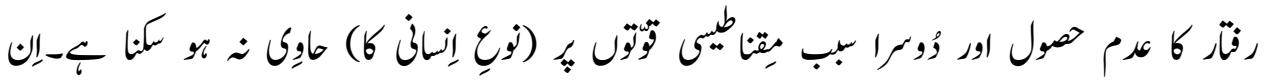

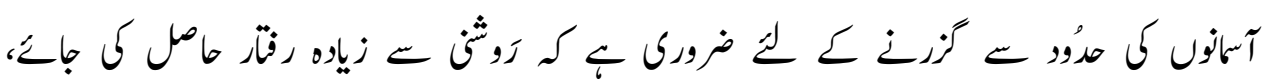

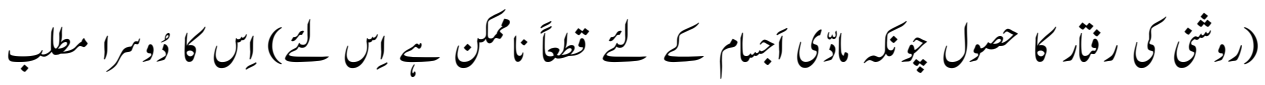

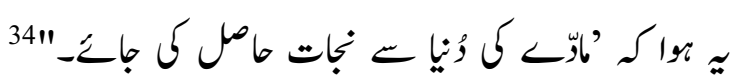

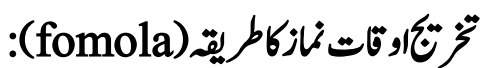

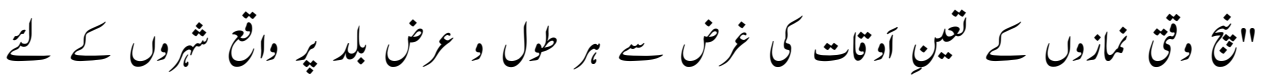

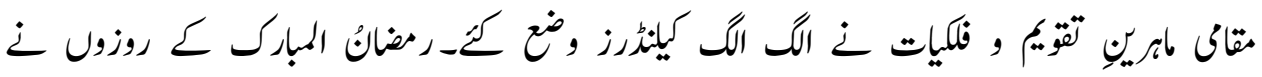

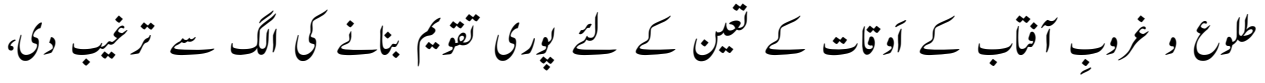

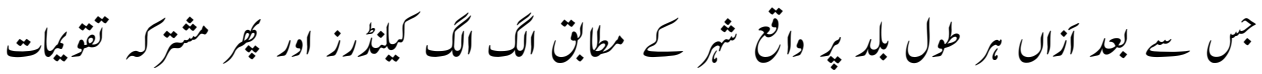

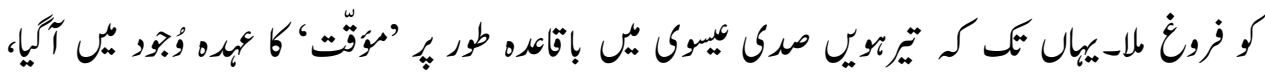

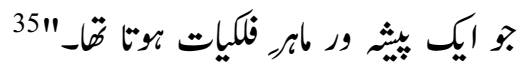

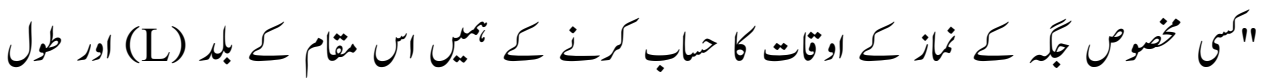

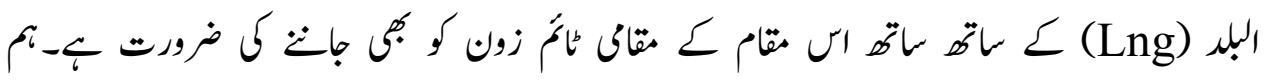

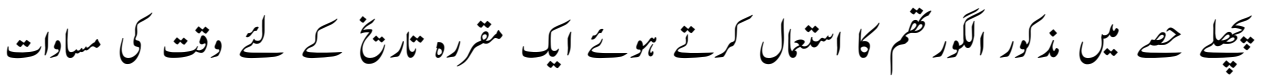
(EQT)

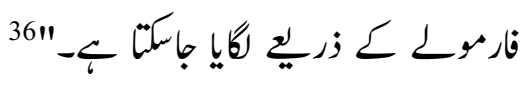
.Lng / 15 - EqT -

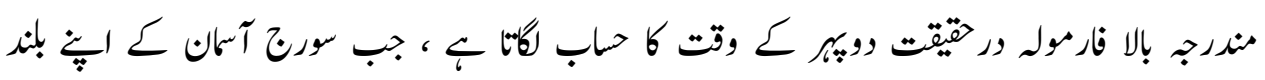

${ }^{34}$ Islam aor Jadeed Science, P-353

${ }^{35}$ Ibid, P-86

${ }^{36}$ https://www.urduweb.org/mehfil/threads/\%DA\%A9\%D8\%B3\%DB\%8 


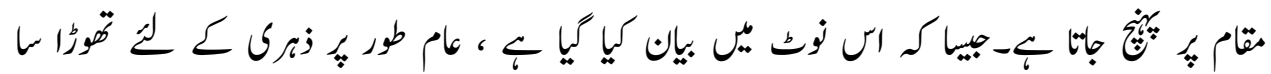

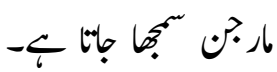

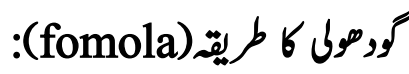

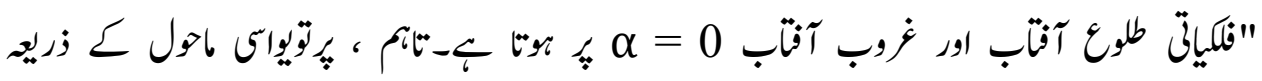

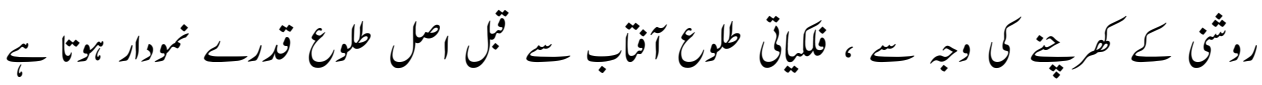

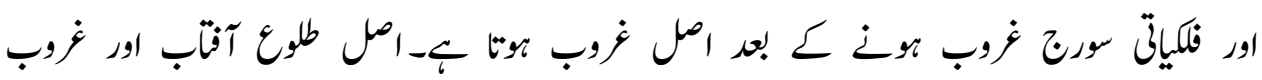

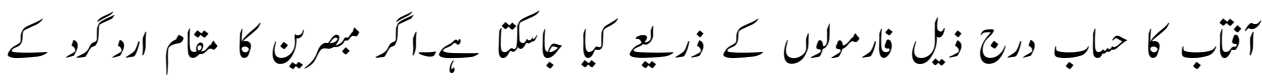

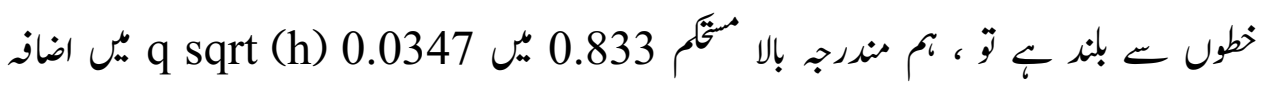

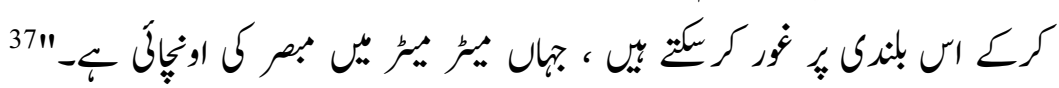

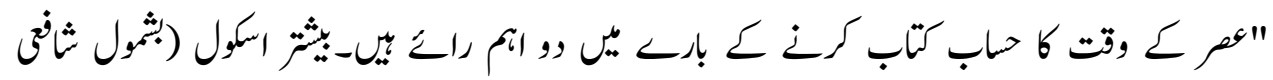

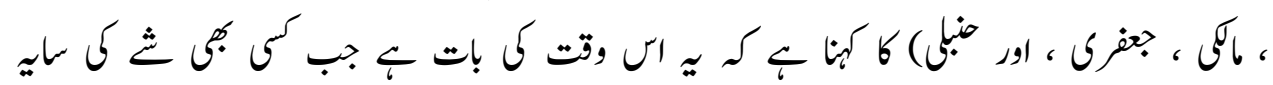

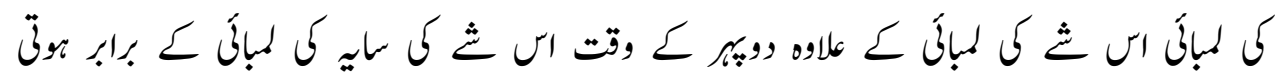

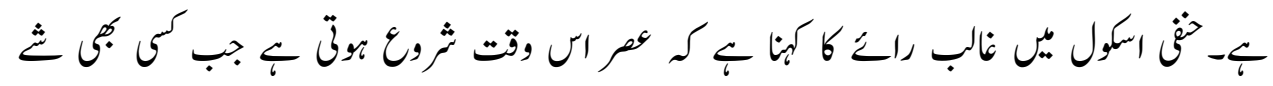

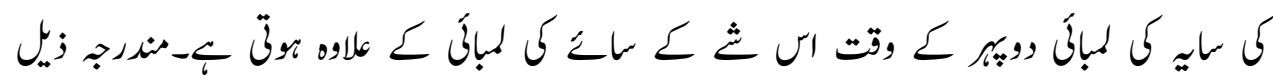

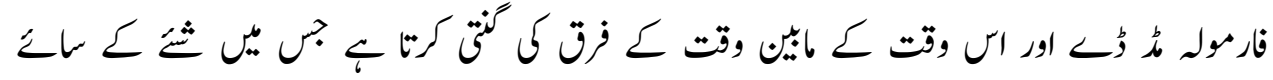

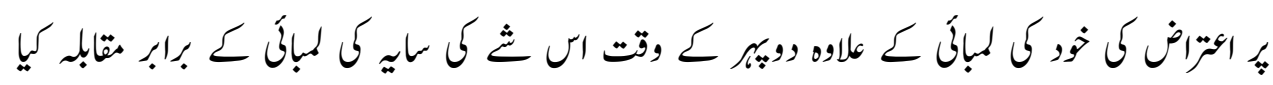

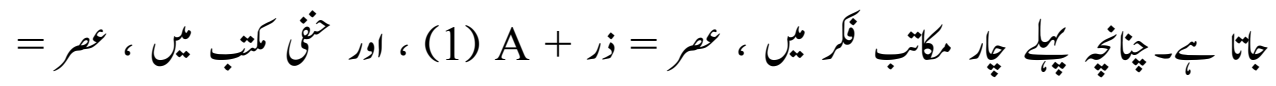

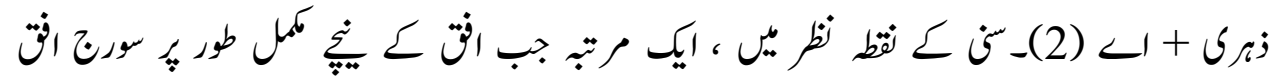

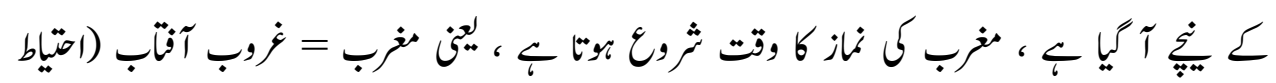

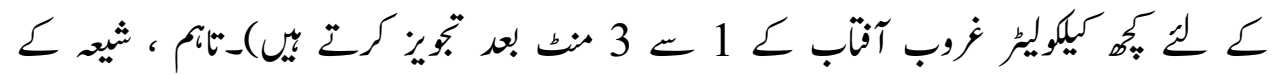

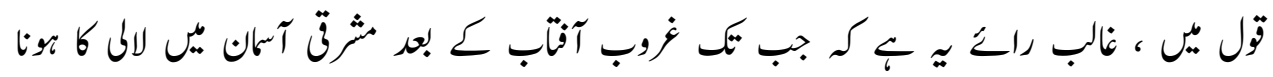

${ }^{37}$ IbidÉ 


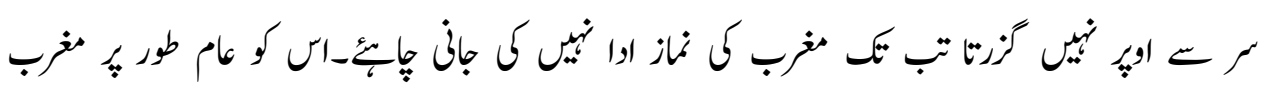

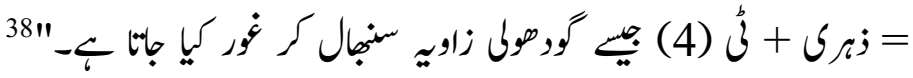

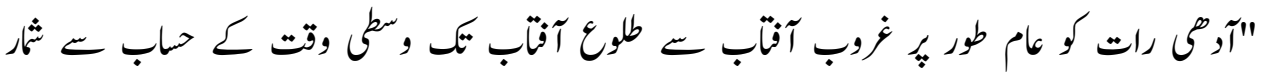

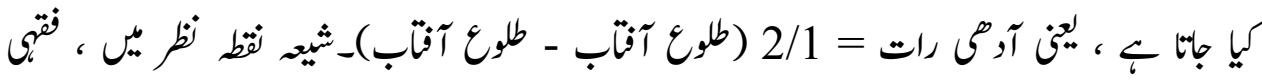

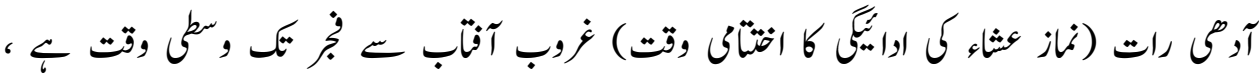

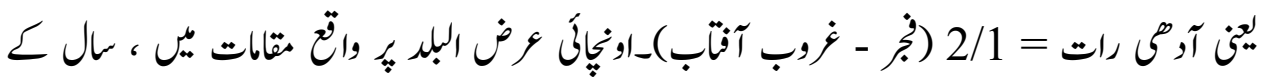

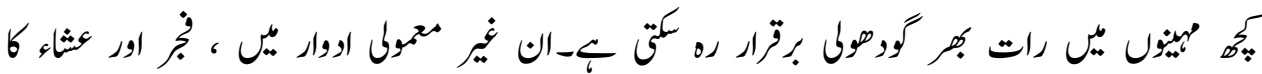

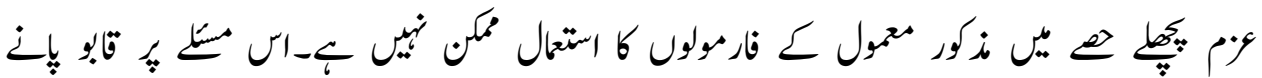

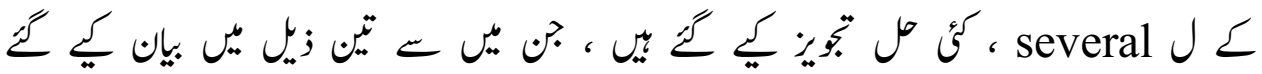

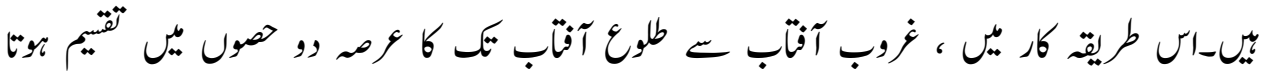

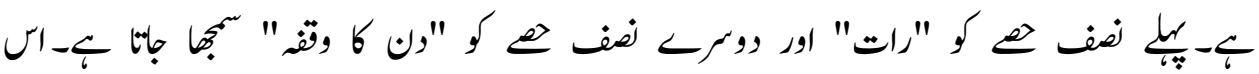

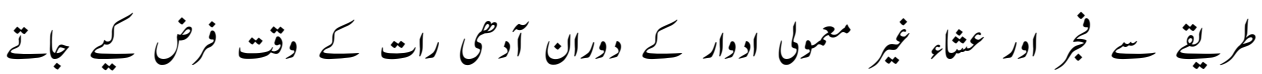

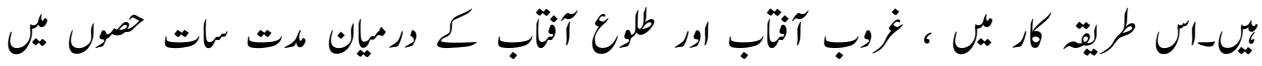

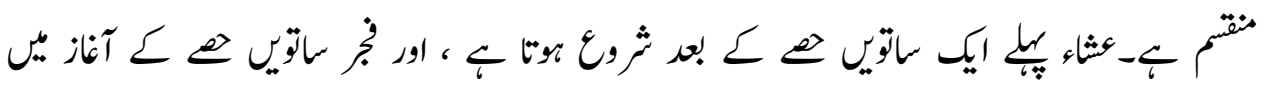

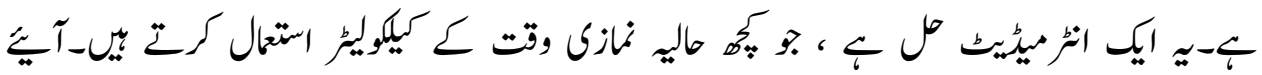

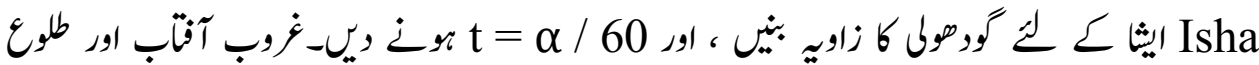

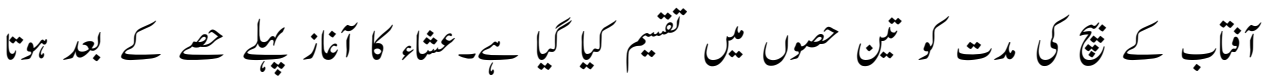

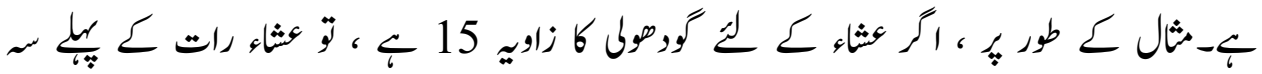

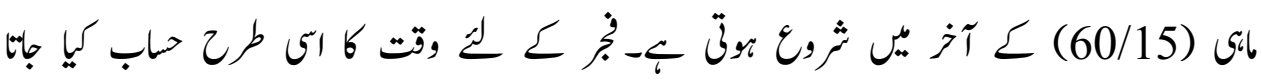




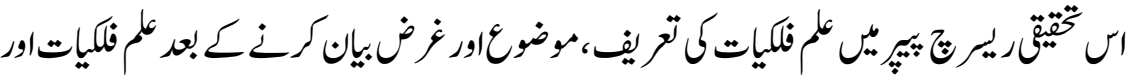

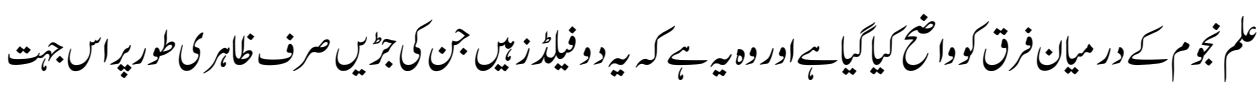

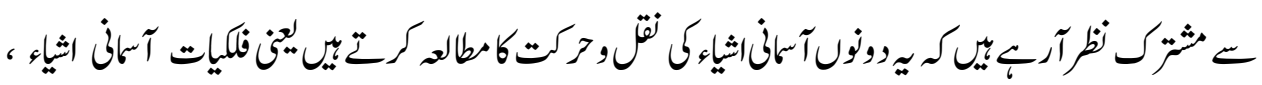

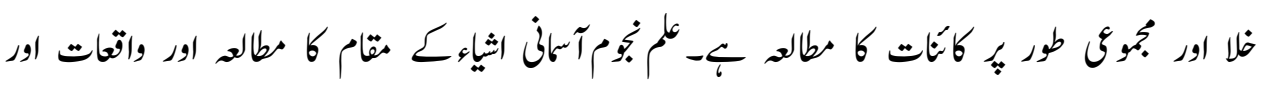

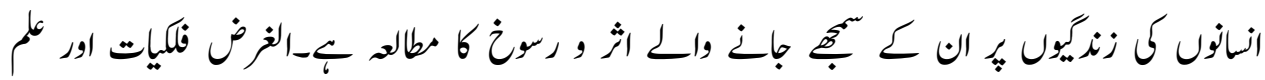

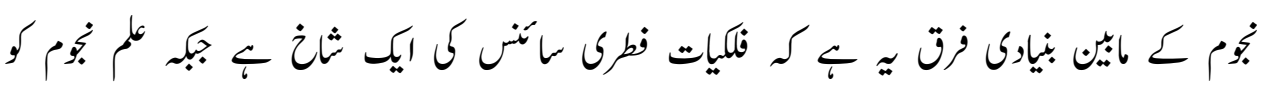

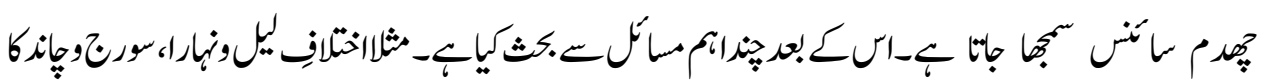

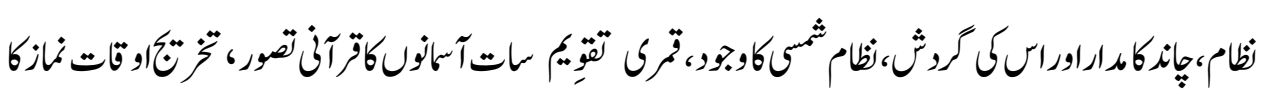

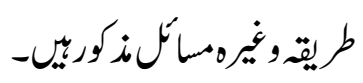

\section{(c) (1) (O)}

Attribution-NonCommercial-ShareAlike 4.0 International (CC BY-NC-SA 4.0) 